University of Wollongong

Research Online

Faculty of Engineering and Information

Faculty of Engineering and Information

Sciences - Papers: Part B

Sciences

2019

Characterizing deformation behaviour of an oxidized high speed steel: Effects of nanoindentation depth, friction and oxide scale porosity

Guanyu Deng

University of Wollongong, gdeng@uow.edu.au

Anh Kiet Tieu

University of Wollongong, ktieu@uow.edu.au

Lihong Su

University of Wollongong, lihongsu@uow.edu.au

Hongtao Zhu

University of Wollongong, hongtao@uow.edu.au

Qiang Zhu

University of New South Wales, qiangz@uow.edu.au

See next page for additional authors

Follow this and additional works at: https://ro.uow.edu.au/eispapers1

Part of the Engineering Commons, and the Science and Technology Studies Commons

Research Online is the open access institutional repository for the University of Wollongong. For further information contact the UOW Library: research-pubs@uow.edu.au 


\title{
Characterizing deformation behaviour of an oxidized high speed steel: Effects of nanoindentation depth, friction and oxide scale porosity
}

\author{
Abstract \\ In the present paper, a systematic study on the deformation behaviour of an oxidized high speed steel \\ (HSS) during nanoindentation has been conducted. Specimens cut from a HSS work roll were oxidized \\ first to develop the oxide layer with thickness close to that built up on a HSS work roll surface during hot \\ rolling in industry. Then, nanoindentation tests with three typical peak loads from low to high (namely 2 \\ $\mathrm{mN}, 20 \mathrm{mN}$, and $200 \mathrm{mN}$ ) were conducted on the oxide scale surface. Porosity in oxide scale and its \\ surface morphology features were examined by transmission electron microscopy (TEM) and scanning \\ electron microscopy (SEM), respectively. In addition, a finite element model was developed and verified by \\ comparing with the experimental measured load-depth curves. With the developed model, for the first \\ time, a systematic investigation has been done to understand the effects of nanoindentation depth (from \\ $10 \mathrm{~nm}$ to $1250 \mathrm{~nm}$ ), friction coefficient (from 0 to 0.6 ) and initial porosity of oxide scale (from 0 to $20 \%$ ) \\ during nanoindentation on the deformation behaviours of both oxide scale and HSS substrate. It has been \\ found an obvious size effect and three regions can be divided according to nanoindentation depth, based \\ on the evolution of mechanical property, porosity in oxide scale, and plastic deformations in both oxide \\ scale and HSS substrate. This study also revealed that friction has a slight influence during \\ nanoindentation and almost the same results were obtained when the friction coefficient is larger than \\ 0.3. By contrast, a large influence of porosity in oxide scale was observed.

\section{Disciplines} \\ Engineering | Science and Technology Studies

\section{Publication Details} \\ Deng, G. Y., Tieu, A. K., Su, L. H., Zhu, H. T., Zhu, Q., Zamri, W. F. H. \& Kong, C. (2019). Characterizing \\ deformation behaviour of an oxidized high speed steel: Effects of nanoindentation depth, friction and \\ oxide scale porosity. International Journal of Mechanical Sciences, 155 267-285.
}

\section{Authors}

Guanyu Deng, Anh Kiet Tieu, Lihong Su, Hongtao Zhu, Qiang Zhu, W Wan Zamri, and Charlie Kong 


\title{
Characterizing deformation behaviour of an oxidized high speed steel:
}

\section{Effects of nanoindentation depth, friction and oxide scale porosity}

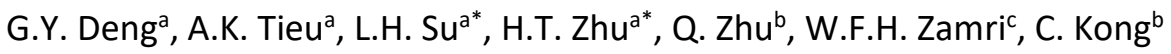

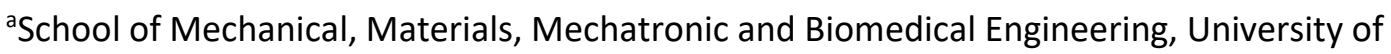 \\ Wollongong, New South Wales 2522, Australia \\ ${ }^{b}$ Electron Microscope Unit, University of New South Wales, New South Wales 2052, Australia \\ 'Department of Mechanical and Materials, Faculty of Engineering and Built Environment, \\ University Kebangsaan Malaysia, Malaysia
}

Corresponding author: lihongsu@uow.edu.au; hongtao@uow.edu.au;

\begin{abstract}
:
In the present paper, a systematic study on the deformation behaviour of an oxidized high speed steel (HSS) during nanoindentation has been conducted. Specimens cut from a HSS work roll were oxidized first to develop the oxide layer with thickness close to that built up on a HSS work roll surface during hot rolling in industry. Then, nanoindentation tests with three typical peak loads from low to high (namely $2 \mathrm{mN}, 20 \mathrm{mN}$, and $200 \mathrm{mN}$ ) were conducted on the oxide scale surface. Porosity in oxide scale and its surface morphology features were examined by transmission electron microscopy (TEM) and scanning electron microscopy (SEM), respectively. In addition, a finite element model was developed and verified by comparing with the experimental measured load-depth curves. With the developed model, for the first time, a systematic investigation has been done to understand the effects of nanoindentation depth (from $10 \mathrm{~nm}$ to $1250 \mathrm{~nm}$ ), friction coefficient (from 0 to 0.6 ) and initial porosity of oxide scale (from 0 to $20 \%$ ) during nanoindentation on the deformation behaviours of both oxide scale and HSS substrate. It has been found an obvious size effect and three regions can be divided according to nanoindentation depth, based on the evolution of mechanical property, porosity in oxide scale, and plastic deformations in both oxide scale and HSS substrate. This study also revealed that friction has a slight influence during nanoindentation and almost the same results were obtained when the friction coefficient is larger than 0.3. By contrast, a large influence of porosity in oxide scale was observed.
\end{abstract}

Keywords: Hot rolling, high speed steel, nanoindentation, oxide scale, friction, porosity 


\section{Introduction}

Thermal oxidation of steel strips and work rolls can cause severe problems and cannot be avoided during industrial hot rolling process because strips always have very high temperatures before entering a rolling mill. According to studies [1-2], the strip temperature varies between $900-1200{ }^{\circ} \mathrm{C}$ depending on strip material and hot rolling process parameters. By contrast, work roll surface has lower temperatures which evolve cyclically due to contact with hot strip in roll bite region and subsequent water cooling in each rotation. It has been found that the maximum temperature at work roll surface could be higher than $600{ }^{\circ} \mathrm{C}[3-6]$. Therefore, high speed steel (HSS) work rolls are increasingly used in industry because they have much better high temperature properties (including hardness and wear resistance) than those of high chromium steel rolls or indefinite chill iron rolls [7-10].

In order to improve the product surface quality and extend work roll service life, oxidation behaviour of HSS materials has been studied since twenty years ago. A number of reports [7,11-20] have revealed that oxidation of HSS materials could be influenced by many factors, such as chemical composition, oxidation duration, atmosphere, pressure and so on. It has been found that temperature and humidity play the most critical roles in oxide thickness, phase constitution and its surface morphology: (i) HSS materials are oxidized very slowly when temperature is less than $600{ }^{\circ} \mathrm{C}$ but accelerated when temperature is higher than $650{ }^{\circ} \mathrm{C}$ $[13,15,16,19]$; (ii) the presence of water vapour in the atmosphere always increases the oxidation rate, particularly at temperatures above $600{ }^{\circ} \mathrm{C}[7,11,14,15,18]$. Zhu et al. [15] has provided an experimental evidence that oxidation initiated at the interface between carbides and matrix regardless of temperature and humidity, by in-situ observations using a high temperature microscope. According to Monteiro et al. [11], the oxidation rate can be effectively reduced by increasing $\mathrm{Cr}$ content, but there are no obvious changes with contents of $\mathrm{V}$ and $\mathrm{W}$ elements.

Unlike the chemical lubricants during hot rolling [21], oxide scale can be considered as a protective coating to reduce heat transfer and wear of work roll surface [22]. But it can also spoil the surface quality of both product and work roll because of buckling and spallation happened during thermal cycles [23-25]. These studies suggest that the performance of oxide scales is highly dependent on their microstructure features and mechanical properties. It should be noted that there are very limited reports available on the mechanical properties of oxide scales, particularly on the oxide scales at work roll surface, because they have very thin scale and it is difficult to use conventional testing techniques. Recently, Zamri et al. $[26,27]$ 
have successfully obtained mechanical properties of an oxide scale on a HSS material with a help of nanoindentation technique, which is based on the continuous recording of applied force and resulting depth of an indenter and has been considered as a reliable method to evaluate a material's mechanical response to load [28-30]. In fact, the oxide scale on work roll surface undergoes very complicated loads during contact with strips in the roll bite region, including tension, compression and shear. According to the microscopy examinations of an industrial HSS work roll, features of indentation and scratch at the roll surface have also been found, which should be induced by those very hard flaked off carbides or oxide particles $[6,7]$. It is worthy to note that, very limited studies on the indentation behaviour of an oxide scale have been reported by now. Even through nanoindentations of oxide scale have been reported by Zamri et al. [26,27], they only conducted tests on the cross-section of the oxide scale rather than at oxide scale surface. They aimed to obtain the mechanical properties of the oxide scale and they did not consider the deformation of steel substrate and its influence, which in fact is very important. In addition, their oxide scale was too thick (over $20 \mu \mathrm{m}$ ) which was not able to form at work roll surface under industrial hot rolling conditions. They have used a very narrow range of loads (only 5-20 mN) in their reports. It should be noted that deformation feature and fracture of a film/substrate system was strongly related to the applied indentation load or depth [31,32]. Besides, influences of friction and oxide scale porosity were not considered in those studies.

Therefore, in order to consider both the nanoindentation behaviour of oxide scale and deformation response of HSS substrate under the realistic contact condition at work roll surface during hot rolling, this study is specifically designed. First, an oxide scale on a HSS substrate with its thickness similar to an industrial case has been developed. Then, nanoindentation tests on the oxide scale surface were carried out in a wide load range. After that, microstructural features of the oxide scale (thickness of the oxide scale and its initial porosity) were characterized using transmission electron microscopy (TEM) and surface morphology of the oxide scale was characterized using scanning electron microscopy (SEM), respectively. Besides, a finite element model considering porous plasticity was developed and verified by the experimental measurements. With the help of this developed model, for the first time, effects of nanoindentation depth, friction and initial porosity of oxide scale were systematically examined. Their influences on the evolutions of load-depth curve, oxide scale porosity and plastic deformation in both oxide scale and HSS substrate have been discussed in details. 


\section{Theoretical background}

\subsection{Theory of nanoindentation}

An understanding of nanoindentation begins with a study of contact mechanics between solid bodies, and the basic analysis has its foundation in the elastic contact theory [28]. Hertz [33] developed a method to analyse the problem of elastic contact between two spherical surfaces with different radii and elastic constants, and he calculated the radius of the circle of contact $a$ in terms of the load $P$ by:

$$
a^{3}=\frac{3}{4} \frac{P R}{E_{r}}
$$

where $R$ indicates the effective radius, $E_{r}$ is the reduced elastic modulus considering elastic deformations in both specimen and indenter and it can be written as:

$$
\frac{1}{E_{r}}=\frac{\left(1-v_{S}^{2}\right)}{E_{S}}+\frac{\left(1-v_{i}^{2}\right)}{E_{i}}
$$

$E_{S}$ is the elastic modulus of specimen, $v_{S}$ is the Poisson's ratio of specimen, $E_{i}$ is the elastic modulus of indenter, and $v_{i}$ is the Poisson's ratio of indenter.

Based on the Hertz elastic contact theory, Sneddon [34] has proposed a general relation among the load, depth and contact area:

$$
P=\alpha h^{m}
$$

where $h$ is the elastic depth of indenter, and $\alpha$ and $m$ are power law fitting constants.

Since 1970s, nanoindentation has attracted wide interest in experimental investigation and this technique has been further developed to measure the elastic modulus and hardness of a material (particular thin films or coatings) during one cycle of loading and unloading [28-30]. Fig. 1a shows a typical nanoindentation load-depth $(P-h)$ curve, plotting evolution of the applied force as a function of the indentation depth. Fig. $1 b$ and $c$ shows the Berkovich indenter geometry and illustration of nanoindentation cross-section. $h_{\max }$ is the peak indentation depth at the peak load $P_{\max }, h_{r}$ is the residual indentation depth after unloading, and $h_{s}$ is the difference between the total depth $\mathrm{h}$ and contact depth $h_{c}$.

By analysing the upper portion of unloading $P$-h curve as shown in Fig. 1a, the stiffness of contact between indenter and specimen can be calculated by [29]: 


$$
S=\frac{d P}{d h}
$$

and the reduced elastic modulus can then be calculated by:

$$
E_{r}=\frac{\sqrt{\pi}}{2 \beta} \frac{S}{A}
$$

where parameter $A$ is the projection of the contact area during nanoindentation and $\beta$ is a dimensionless parameter depending on the indenter geometry. Details in determination of load frame compliance and diamond area function can be found in previous studies by Oliver and Pharr $[29,30]$. The area function for a Berkovich indenter can be expressed by

$$
\begin{aligned}
& A\left(h_{c}\right)=C_{0} h_{c}^{2}+\sum_{i=1}^{8} C_{i} h_{c}^{1 / 2^{(i-1)}} \\
& C_{0}=3 \sqrt{3} \tan ^{2} \theta \\
& h_{c}=h_{\max }-\varepsilon\left(h_{\max }-h_{r}\right)
\end{aligned}
$$

The first term in Eq. (6) describes a perfect Berkovich indenter, and the others account for the tip rounding and other variations from the ideal geometry shape. Parameters $\theta, C_{0}$ and $\varepsilon$ are constants depending on indenter geometry. For a Berkovich indenter, $\theta$ indicates the face angle of indenter and $C_{0}$ is about 24.56. Parameter $\varepsilon$ in Eq. (8) depends on the indenter geometry, it is 0.75 for a Berkovich indenter while 0.72 for a conical indenter [28,29].

Substituting Eqs. (5) and (6) into Eq. (2), the elastic modulus of specimen can be written by

$$
E_{S}=\frac{1-v_{S}^{2}}{\frac{2 \beta A d h}{\sqrt{\pi} d P}-\frac{\left(1-v_{i}^{2}\right)}{E_{i}}}
$$

The mean contact pressure, $P_{m}$, calculated as a function of the indentation strain (ratio of the contact radius $a$ over the indenter radius $R$ ) is

$$
P_{m}=\frac{4}{3} \frac{E_{r}}{\pi} \frac{a}{R}
$$

According to Eq. (5) and Eq. (10), the relation between the mean contact pressure and indentation strain can be rewritten as

$$
P_{m}=\frac{2 S}{3 \beta A} \frac{1}{\sqrt{\pi}} \frac{a}{R}
$$

Nanohardness of specimen $(H)$ can be calculated using the following equation $[29,30]$ : 


$$
H=\frac{P_{\max }}{A}
$$

From these equations, elastic modulus and nanohardness of a material can be determined based on nanoindentation analysis, once its Poisson's ratio $v_{s}$ is known. It has been often assumed as 0.2 for ceramic materials and 0.3 for metallic materials [27].

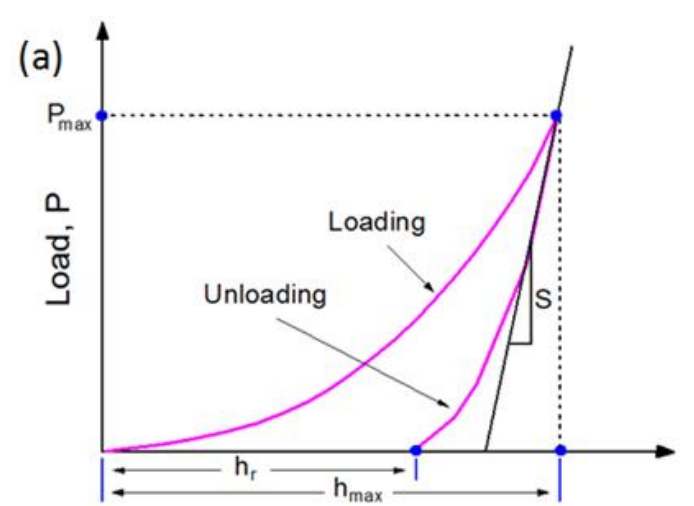

(b)

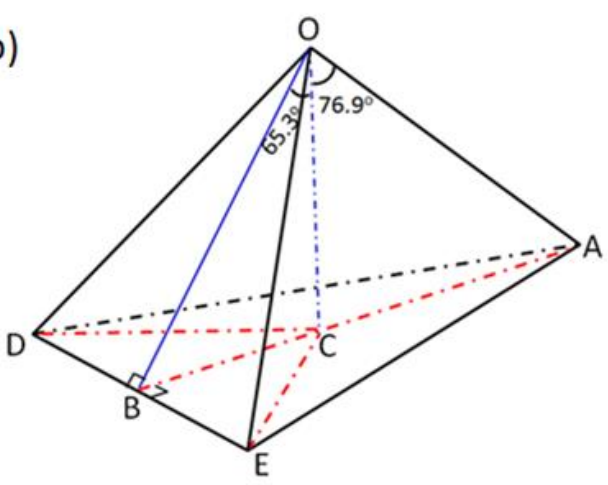

Displacement, $\mathrm{h}$

(c)

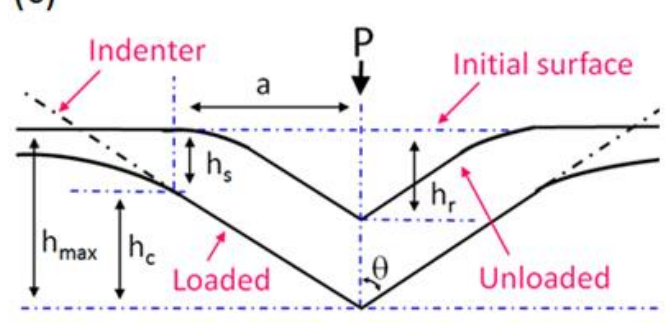

(d)

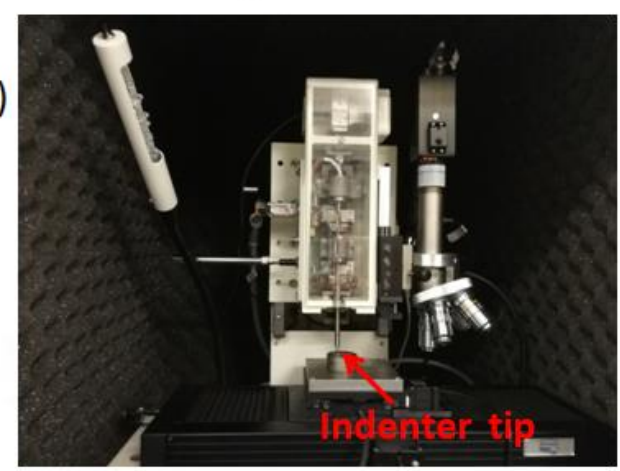

Fig. 1 (a) Typical nanoindentation load-depth $(P-h)$ curve during loading and unloading segments, (b) geometry of a Berkovich indenter tip, (c) schematic illustration of a nanoindentation cross-section, (d) photo of the IBIS/UMIS nanoindentation system applied for experiments in this study.

\subsection{Description of porous plasticity material model}

Over the last 50 years, plasticity of the porous materials has been a subject of intensive investigations and there are two main primary directions: (i) plasticity at small overall strains (determination of the macroscopic yield surface in stress space accounting for porosity) [35]; and (ii) considering void growth and coalescence at much larger overall strains [36]. This section provides a brief description about the Gurson-type porous plasticity model, which is the most widely used micromechanical model initially proposed by Gurson and further improved by Tvergaard and Needleman [37-39]. The yield function of this model is expressed by

$$
\varnothing\left(f, \sigma_{y}, p, q\right)=\frac{q^{2}}{\sigma_{y}^{2}}+2 q_{1} f^{*}(f) \cosh \left(-q_{2} \frac{3 p}{2 \sigma_{y}}\right)-1-q_{3} f^{* 2}(f)=0
$$


where $f$ is the void volume fraction and it is the average measure of a void-matrix aggregate, $f^{*}$ is a porosity function describing the evolution $f, \sigma_{y}$ is the yield stress governing flow of the matrix material, $p$ is the macroscopic hydrostatic pressure, $q$ is the conventional von Mises equivalent stress. Parameters $q_{1}, q_{2}$ and $q_{3}$ are constants to account for void interaction effects due to multiple-void arrays and to provide a better agreement with experimental results.

In Eq. (13), $f$ indicates the current void volume fraction, and the evolution of the void volume fraction can be divided into two contributions, namely the growth of existing voids $\left(f_{g}\right)$ and the nucleation of new voids $\left(f_{n}\right)$. The void growth is based on the bulk material incompressibility under plastic deformation, while the void nucleation is dependent on the stress or strain conditions. The following mathematical relationships are applied,

$$
\begin{gathered}
\dot{f}=\dot{f}_{g}+\dot{f}_{n} \\
\dot{f}_{g}=(1-f) \dot{\varepsilon}_{k k} \\
\dot{f}_{n}=\frac{F_{n}}{S_{n} \sqrt{2 \pi}} \exp \left[-\frac{1}{2}\left(\frac{\varepsilon_{m}^{p}-\varepsilon_{n}}{s_{n}}\right)^{2}\right] \dot{\varepsilon}_{m}^{p}
\end{gathered}
$$

where $\dot{\varepsilon}_{k k}$ indicates the plastic strain rate, $\varepsilon_{m}^{p}$ indicates the equivalent plastic strain of matrix material, $F_{n}$ represents the void nucleating particles fraction, $\varepsilon_{n}$ and $S_{n}$ represent the mean value and standard deviation of the strain.

Aiming to account for the rapid drop in stress carrying capacity or void coalescence, Tvergaard and Needleman replaced parameter $f$ using a bilinear effective porosity function $\left(f^{*}(f)\right)$ as following [39],

$$
f^{*}(f)=f(x)=\left\{\begin{array}{lcrr}
f & \text { for } & f \leq f_{c} \\
f_{c}+\frac{\left(q_{1}+\sqrt{q_{1}^{2}-q_{3}}\right) / q_{3}-f_{c}}{f_{f}-f_{c}}\left(f-f_{c}\right) & \text { for } & f_{c}<f<f_{f} \\
\left(q_{1}+\sqrt{q_{1}^{2}-q_{3}}\right) / q_{3} & \text { for } & f \geq f_{f}
\end{array}\right.
$$

where $f_{c}$ is the critical void volume fraction at which voids begin to coalesce and the material softening is accelerated, and $f_{f}$ denotes the void volume fraction after the complete failure and the material loses all stress carrying capacity. The term $f_{c}<f<f_{f}$ describes the mechanisms such as void coalescence and development of micro-fractures. 
Pressure in the yield conditions as shown in Eq. (13) leads to non-deviatoric plastic strains, and plastic flow is assumed to be normal to the yield surface. The hardening of the matrix material can be described through

$$
\sigma_{y}=\sigma_{y}\left(\varepsilon_{m}^{p}\right)
$$

The evolution of the equivalent plastic strain $\left(\varepsilon_{m}^{p}\right)$ in the matrix material is assumed to be governed by enforcing equality between the rates of macroscopic plastic work and the matrix plastic dissipation [39],

$$
(1-f) \sigma_{y} \dot{\varepsilon}_{m}^{p}=\sigma_{i j} \dot{\varepsilon}_{i j}^{p}
$$

\section{Material and experiment}

The studied material was a hot rolling work roll grade HSS material, mainly containing $1.78 \%$ C, $5.0 \% \mathrm{Cr}, 0.55 \% \mathrm{Mn}, 3.7 \% \mathrm{Mo}, 0.69 \% \mathrm{Si}, 5.2 \% \mathrm{~V}$, and $0.52 \% \mathrm{Ni}[6]$. This material has about $10.5 \%$ vanadium and chromium carbides based on X-ray diffraction (XRD) analysis [7]. HSS specimens with dimension of $15 \times 15 \times 5 \mathrm{~mm}^{3}$ were cut from a broken hot rolling work roll and the average Vickers microhardness is about $780 \mathrm{Hv}$. These HSS specimens were carefully ground and polished using a standard method before isothermal oxidation. The oxidation experiments were conducted at $600^{\circ} \mathrm{C}$ in a dry atmosphere for half an hour based on previous study [20], which showed that such the oxidation condition resulted into the oxide scale with similar thickness to that observed at HSS work roll surface after industrial hot rolling.

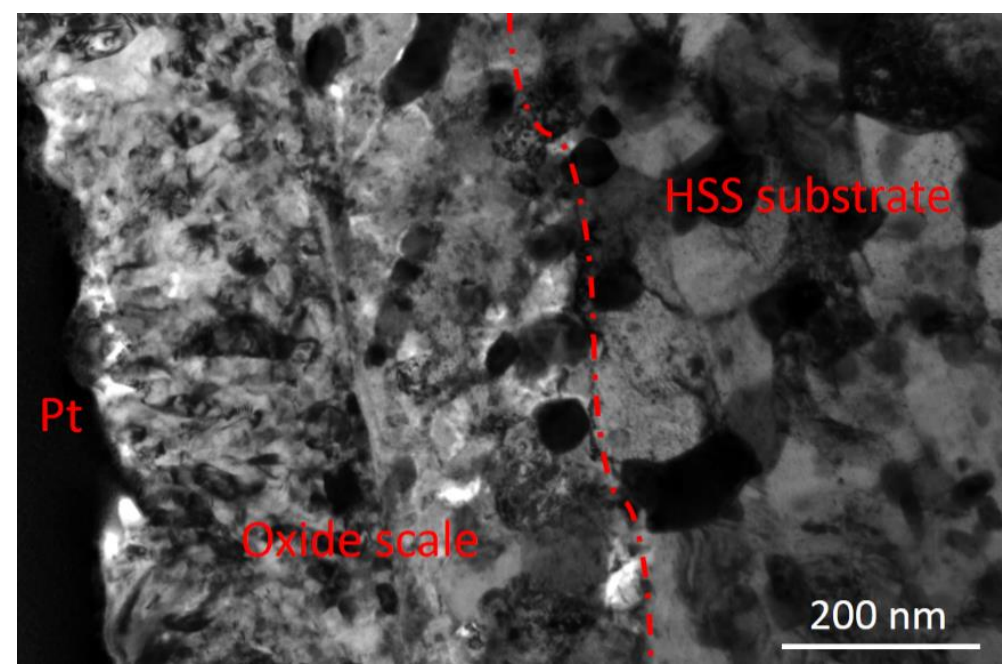

Fig. 2 Typical cross-sectional microstructure of the studied oxide scale by TEM observation before nanoindentation. 
Nanoindentation tests were conducted on the oxidized HSS sample surface, using the IBIS/UMIS nanoindentaton system developed by the CSIRO Division of Applied Physics in Sydney. A diamond Berkovich indenter, having geometry of three-sided pyramid with an angle of about $65.27^{\circ}$ between the centreline and three faces, was used. The indenter tip has a curvature with diameter of about $150 \mathrm{~nm}$. Resolutions in loading force and depth during nanoindentation experiments are about $75 \mathrm{nN}$ and $0.05 \mathrm{~nm}$, respectively. Fig. $1 \mathrm{~d}$ shows a photo of the IBIS/UMIS nanoindentation system applied for experiment in this study. The equipment can perform an indentation test in a wide load range from $100 \mu \mathrm{N}$ up to $500 \mathrm{mN}$. Three typical loading forces, namely $2 \mathrm{mN}$ (low load), $20 \mathrm{mN}$ (medium load) and $200 \mathrm{mN}$ (high load), were selected for nanoindentation tests. For each loading force, 25 nanoindentations were carried out in terms of a $5 \times 5$ array across the oxide scale surface. A square root load control mode was chosen where the load was increased gradually until it reached the maximum load and then it was decreased.

Scanning electron microscopy (SEM) was applied to characterize surface morphology of the oxidized HSS samples after nanoindentation tests. Thickness and porosity of the oxide scale on the HSS matrix was determined using transmission electron microscopy (TEM), with the sample prepared by focused ion beam (FIB) technique. It has been found that the average oxide scale thickness is about $517 \mathrm{~nm}$ and close to that developed at HSS work roll surface in industry [7]. The overall porosity in oxide scale is about 4.8\%, estimated from ten TEM crosssectional microstructures of oxide scale based on the fractional area of the pores or voids. Fig. 2 is a TEM image showing the typical cross-sectional microstructure of the oxide scale. These experimental results will be used as input parameters when developing finite element model in the following section.

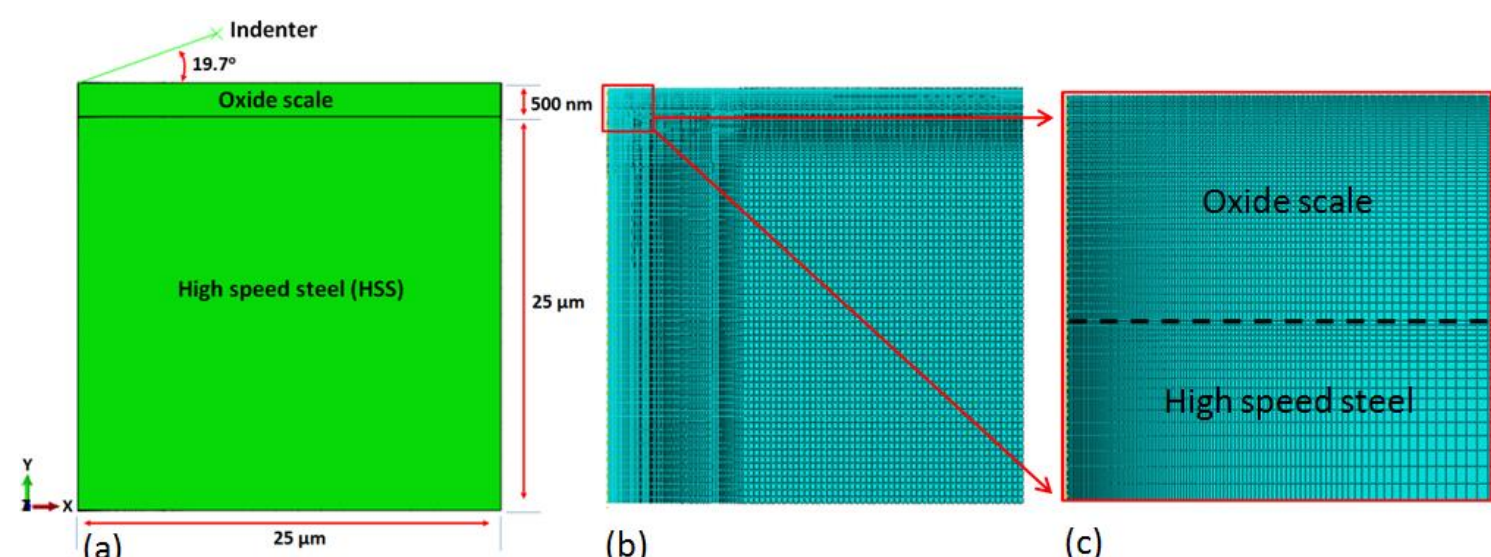

Fig. 3 (a) Schematic illustration of a finite element model about nanoindentation on the surface of an oxidized HSS specimen, (b) detailed mesh conditions of oxide scale and HSS substrate, (c) magnified region as highlighted in (b). 


\section{Finite element simulation}

In previous studies [26,27], Zamri et al. has simulated nanoindentations on the cross-section of a thick oxide scale aiming to obtain mechanical property variations along the thickness direction of the oxide layer. Unfortunately, their models are not able to reflect realistic deformation responses in oxide scale and HSS substrate during practical roll-strip contacts in hot rolling because their oxide scale was too thick and nanoindentations were not applied on the surface. In addition, only very limited loads of $5 \mathrm{mN}$ and $20 \mathrm{mN}$ were applied in those nanoindentations, and influences of friction and oxide scale porosity have not been considered. Therefore, in this study, nanoindentations on the oxide scale surface are simulated using commercial finite element software Abaqus (version 6.11-1).

Fig. 3a shows the schematic illustration of finite element model. Similar to previous reports $[28,40,41]$, the Berkovich indenter geometry was simplified into two-dimension as a cone with a vertex angle of $70.3^{\circ}$ due to the same area-to-depth ratio. The indenter was simulated as an analytical rigid surface with a reference point attached to the tip point due to its very high elastic modulus. The oxide scale and HSS substrate were assumed as deformable bodies, and their interface was considered as perfectly bonded. Oxide scale thickness was set to $500 \mathrm{~nm}$ based on TEM observations. It is worth noting that the simulated oxide scale in this study was assumed to be uniform along its thickness direction and no transition zone between the oxide scale and HSS substrate was considered since it is very thin under practical hot rolling industry conditions. As marked in Fig. 3a, HSS substrate was assumed to have $25 \mu \mathrm{m}$ in length and 25 $\mu \mathrm{m}$ in thickness. The oxide scale and HSS substrate were meshed into 12000 and 8400 elements, respectively. Detailed meshes can be seen in Fig. 3b. The highlighted region under the indenter contact has a higher density of meshes with very fine elements. As illustrated in Fig. $3 c$, the element size was progressively increased towards the far field domain in the specimen model. A four-node bilinear axisymmetric quadrilateral reduced integration element type with hourglass control (element id: CAX4R) was assigned for both oxide scale and HSS substrate. Input parameters of the diamond Berkovich indenter, oxide scale and HSS substrate for finite element simulations in this study were extracted from previous reports [26-28]. The Poisson's ratio of the indenter, oxide scale and HSS was $0.07,0.19$ and 0.3 , respectively. The input elastic modulus and yield strength for the indenter were $1141 \mathrm{GPa}$ and 35.7 GPa, respectively, and $240 \mathrm{GPa}$ and $7.0 \mathrm{GPa}$ for oxide scale, and $210 \mathrm{GPa}$ and $2.0 \mathrm{GPa}$ for HSS substrate. Gurson-type porosity material model in Section 2.2 was used for oxide scale, 
while elasto-plastic material model was used for HSS substrate. The overall porosity was set to $5 \%$ in oxide scale based on TEM observations. Influence of initial porosity has also been studied by simulating porosity in a wide range from 0 to $20 \%$. It should be noted that, presence of the carbides in HSS material has not been considered in the present simulations.

Similar to experiments, the indenter was loaded along the vertical direction ( $\mathrm{Y}$ direction in Fig. 3a) to press into the oxide scale surface and constrained in the horizontal direction ( $X$ direction in Fig. 3a) in simulations. Once a pre-set maximum depth was reached, the indenter was unloaded in a reverse path to its original position. In this study, a wide range of nanoindentation depth from $10 \mathrm{~nm}$ to $1250 \mathrm{~nm}$ were simulated. As illustrated in Fig. 3, nodes on the bottom edge of HSS substrate were constrained in both $X$ and $Y$ directions so that they could not move during the whole nanoindentation process. In order to understand the influence of frictional contact between the indenter and oxide scale, various friction coefficients from $\mu=0$ to 0.6 were studied. To enforce the contact, the deformable oxide scale surface was considered as the slave surface while the rigid indenter surface was considered as the master surface. A total of 54 cases have been simulated in this study.

\section{Results and discussion}

\subsection{Experimental results and model verification}

In this work, nanoindentation tests on the surface of oxidized HSS material were conducted in a $5 \times 5$ array using a low load $(2 \mathrm{mN})$, medium load $(20 \mathrm{mN})$ and high load $(200 \mathrm{mN})$, respectively. Surface morphologies of the oxide scale after nanoindentation tests were characterized by SEM as shown in Fig. 4a-c. It has been seen that HSS substrate is fully covered by oxide layer during the oxidation, which has similar features to the previous oxidation reports [13-16]. It should be noted that nanoindentations at carbides free regions were only considered, away from the oxidized carbides which often protrude above the oxide matrix. It is evident in Fig. $4 a$, loading force of $2 \mathrm{mN}$ leads to very shallow residual indents at oxide scale surface. Some very small pile-ups can be distinguished by carefully observing the edges and corners of these indents. Fig. $4 \mathrm{~b}$ shows the residual indents for the loading force of $20 \mathrm{mN}$. By comparison, they have a much larger size than those indents in Fig. 4a. Geometry differences among the indents in Fig. 4b are still visible, and both pile-up and sink-in can be seen at surface depending on the indent locations. When increasing the loading force up to $200 \mathrm{mN}$, residual indents with very similar size to each other have been obtained as shown in Fig. 4c. However, microcracks developed around some indents as indicated by red arrows in the figure. From Fig. 4, it 
is obvious that nanoindentation load has a large effect on the residual indents in both the geometry shape and size. In addition, indent variations under low load in Fig. 4a or under medium load in Fig. $4 \mathrm{~b}$ should be attributed to inhomogeneous oxidations at HSS surface. As reported in $[9,15-17,20]$, non-uniform oxidation due to short oxidation time leads to variations in the oxide scale thickness.
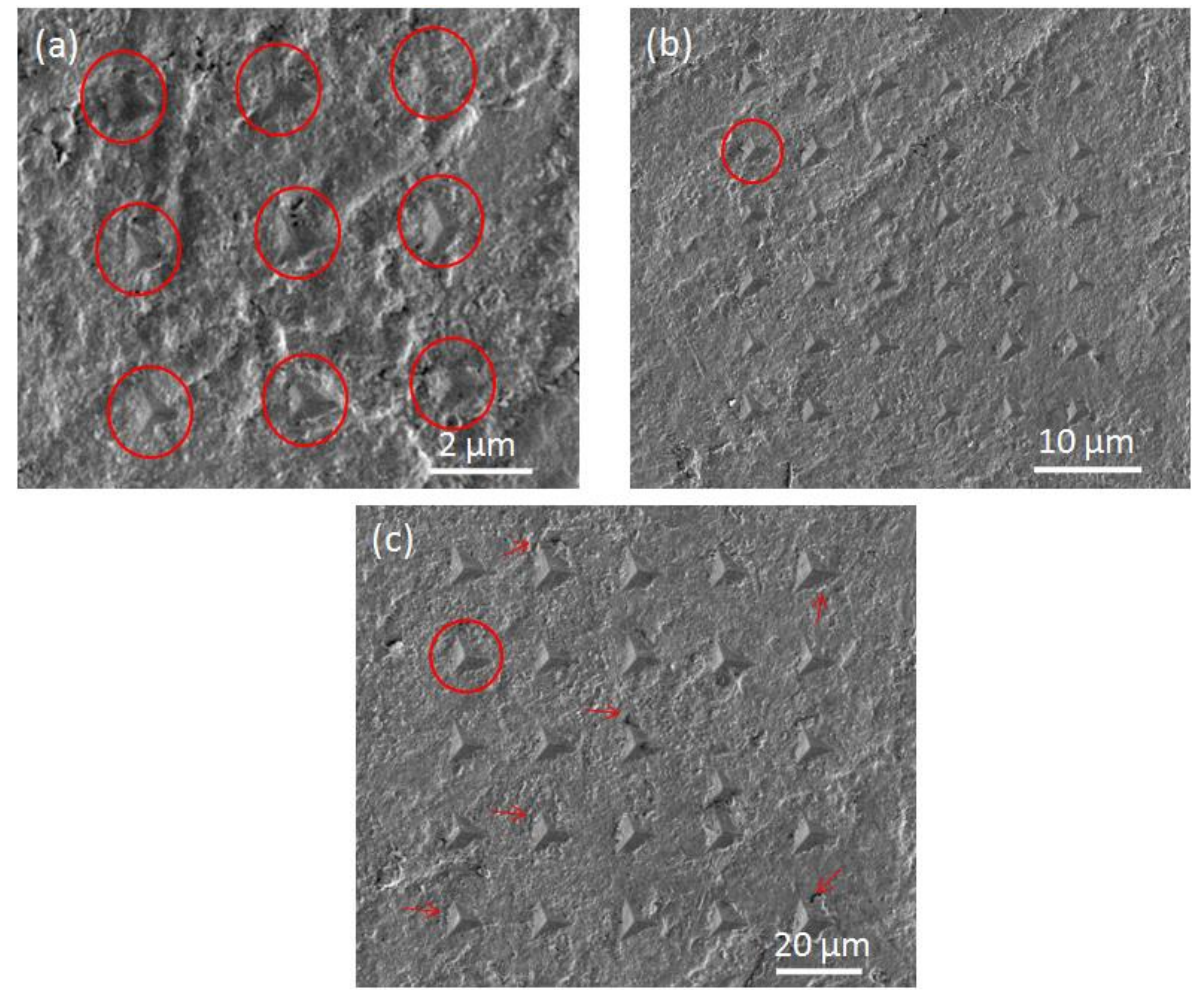

Fig. 4 SEM images of the oxidized HSS specimen surface after nanoindentations under peak loading force $P$ of (a) $2 \mathrm{mN}$, (b) $20 \mathrm{mN}$, and (c) $200 \mathrm{mN}$.

Fig. 5a-c shows the $P$ - $h$ curves obtained by nanoindentation experiments. Fig. $5 \mathrm{a}$ indicates that the maximum nanoindentation depth is about $78.5 \mathrm{~nm}$ and the residual depth is about $50.2 \mathrm{~nm}$ for the low load of $2 \mathrm{mN}$. By comparison, the maximum nanoindentation depth is about $315 \mathrm{~nm}$ for the medium load of $20 \mathrm{mN}$ in Fig. 5b and $1115 \mathrm{~nm}$ for the high load of 200 $\mathrm{mN}$ in Fig. 5c. The corresponding residual depth after unloading is about $248 \mathrm{~nm}$ and $978 \mathrm{~nm}$, respectively. It is worth noting that the maximum indentation depth of $1115 \mathrm{~nm}$ is more than twice of the oxide scale thickness $(517 \mathrm{~nm})$. This confirms that HSS matrix has already been plastically deformed during nanoindentation when the loading force is as high as $200 \mathrm{mN}$. In Refs. $[26,27]$, nanoindentations with $20 \mathrm{mN}$ were also done but on the cross-section of the oxide scale. Their results indicated that the maximum nanoindentation depth was about 250 $\mathrm{nm}$ in the outer oxide sublayer and about $340 \mathrm{~nm}$ in the inner oxide sublayer. The differences 
between this work and studies [26,27] should be due to the differences in oxide microstructure, phase compositions and nanoindentation orientations (from surface or crosssection).

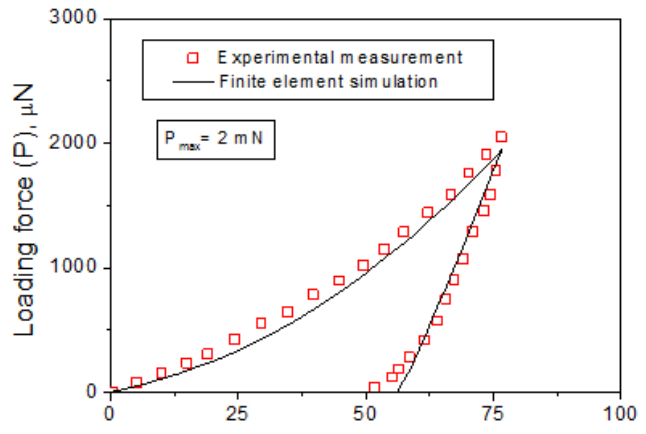

(a) Nanoindentation depth (h), nm

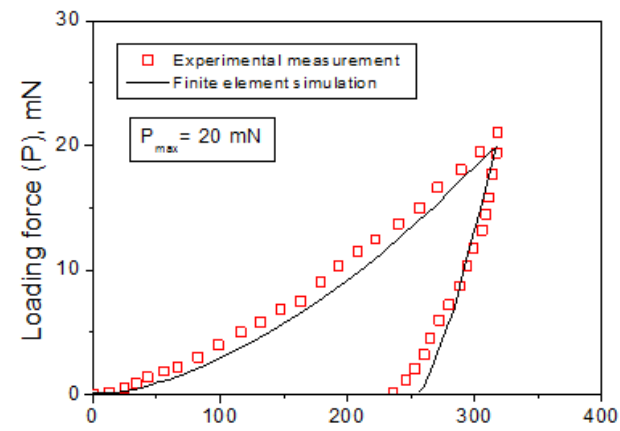

(b) Nanoindentation depth (h), $\mathrm{nm}$

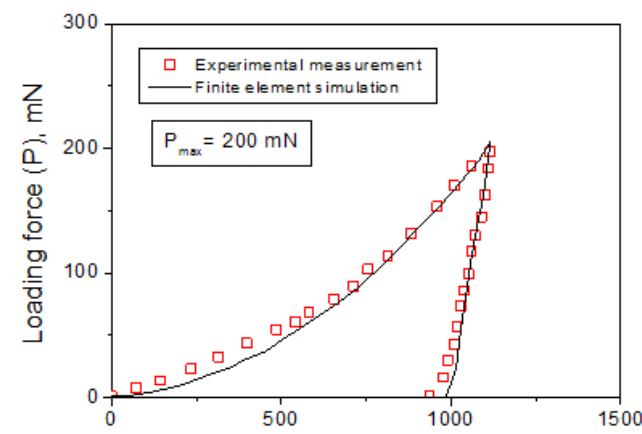

(c) Nanoindentation depth (h), nm

Fig. 5 Comparison of nanoindentation $P$ - $h$ curves between finite element simulation and experiment under the peak loading force $P$ of (a) $2 \mathrm{mN}$, (b) $20 \mathrm{mN}$, and (c) $200 \mathrm{mN}$.

In addition to the experiments, finite element simulations were also conducted based on those three measured maximum nanoindentation depths. The simulated load-depth curves are also plotted in Fig. 5 and compared with the experimental measurements. As can be seen, reasonable agreements between the simulations and experiments have been obtained for all three cases. For a given nanoindentation depth, simulated and measured peak loading forces are close and their difference is less than $5 \%$. Small deviations in both loading and unloading segments for the low load in Fig. 5 should be due to the influence of oxide scale surface morphology and residual stress. Slightly inhomogeneous oxide scale surface is seen in Fig. 4a, but perfectly flat surfaces were assumed in the finite element simulations. Besides, residual stress in the oxide scale as measured in [20] has not been considered in this study, but its influence will be investigated in future. According to the comparison between the simulations and experiments in Fig. 5, it suggests that the present finite element model is reliable to simulate the nanoindentations on the surface of oxidized HSS materials. 


\subsection{Effect of nanoindentation depth}

According to previous experiments and simulations [42-46], mechanical properties of various materials were found to be dependent on the indentation depths. Zamri et al. [26] also obtained different results when they changed the load from $5 \mathrm{mN}$ to $20 \mathrm{mN}$. Therefore, a wide range of nanoindentaton depth from $10 \mathrm{~nm}$ to $1250 \mathrm{~nm}$ are simulated in this section to study its effect, considering the constant friction coefficient of 0.1 and initial porosity of $5 \%$ in oxide layer.

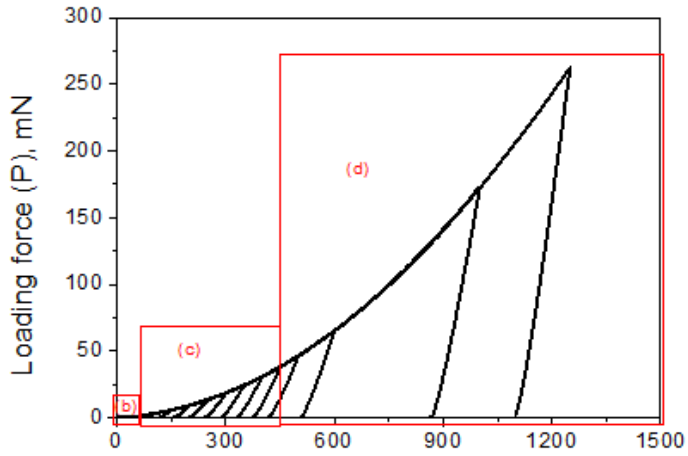

(a) Nanoindentation depth (h), nm

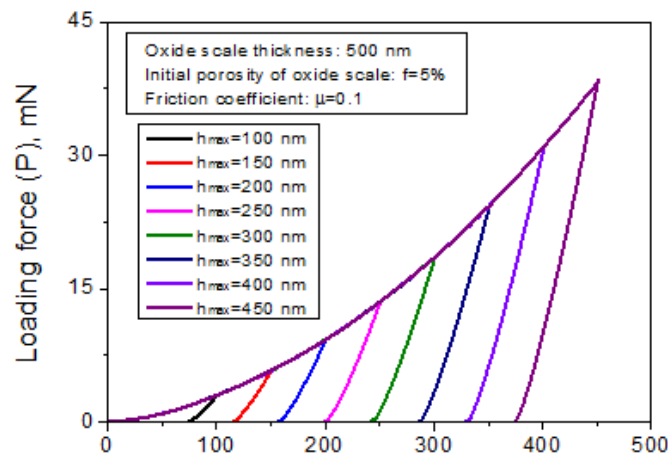

(c) Nanoindentation depth (h), nm

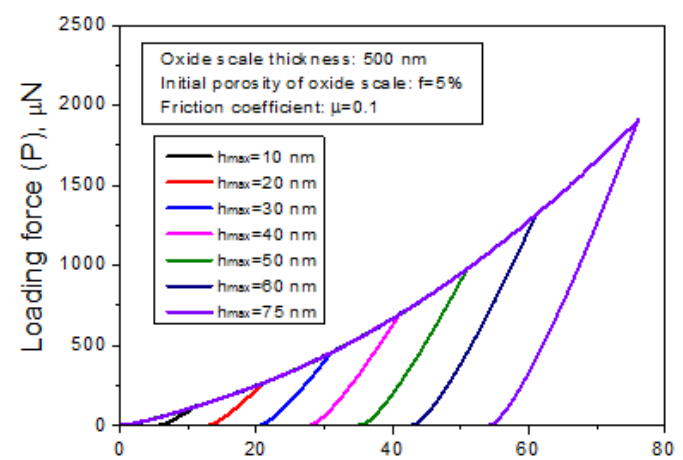

(b) Nanoindentation depth (h), nm

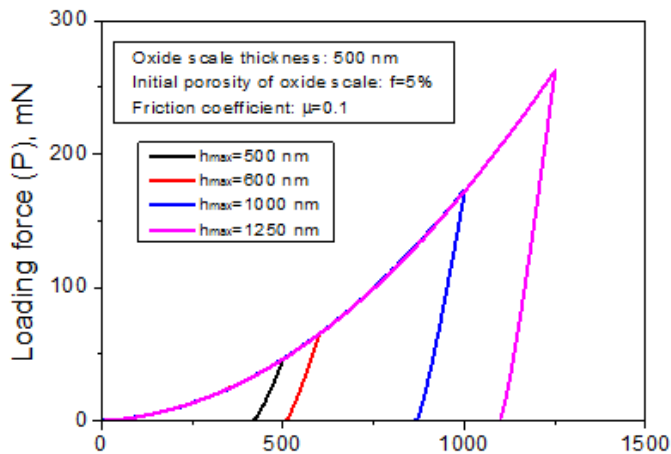

(d) Nanoindentation depth (h), $\mathrm{nm}$

Fig. 6 (a) Overview of $P$ - $h$ curves during nanoindentations of oxidized HSS material under all simulated loads. Magnified $P$ - $h$ curves for the maximum loading depth of (b) $10-75 \mathrm{~nm}$, (c) $100-450 \mathrm{~nm}$, and (d) 500-1250 nm.

Fig. 6a shows an overview of the simulated $P$ - $h$ curves during nanoindentation. In the figure, three regions have been marked according to the maximum loading depth. The corresponding $P-h$ curves for each region have been magnified in Fig. $6 \mathrm{~b}-\mathrm{d}$, respectively. It is obvious that the shape of loading curve follows a similar tendency but the shape of unloading curve changes significantly. The slope of unloading curve increases gradually with the maximum loading depth. 


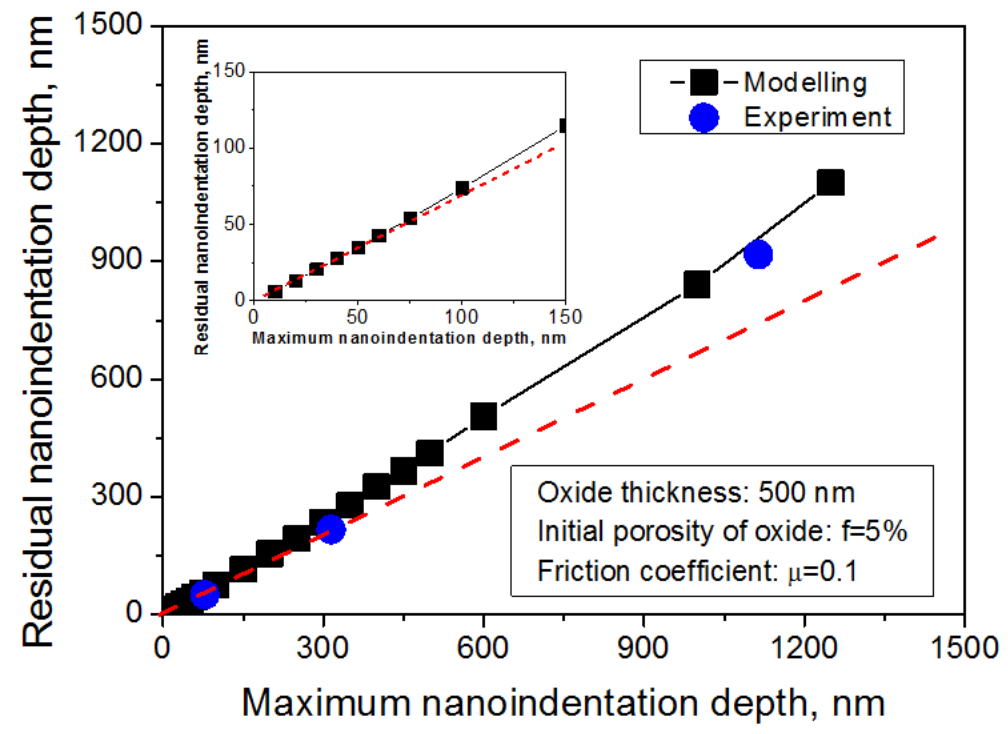

Fig. 7 Plots of residual nanoindentation depth against the maximum loading depth based on finite element simulations and experimental measurements.

Fig. 7 shows the evolution of simulated residual nanoindentation depth against the maximum loading depth. A good linear relationship between them is seen from the magnified figure inserted in Fig. 7 when the maximum loading depth is less than $100 \mathrm{~nm}$, as indicated by the red dashed line. However, with further increasing the nanoindentation depth, the slope deviates gradually leading to a quicker increase into the residual depth. Such a phenomenon should be affected by the presence of HSS substrate below the oxide scale. In order to make a comparison, the experimental measured residual nanoindentation depths indicated by the blue points have also been plotted in Fig. 7. Large deviations from the red dashed line have been seen when the applied load was $20 \mathrm{mN}$ or $200 \mathrm{mN}$, and the deviation increases with the nanoindentation load. In addition, the figure also reveals that the experimental results are slightly lower than the simulated results. 


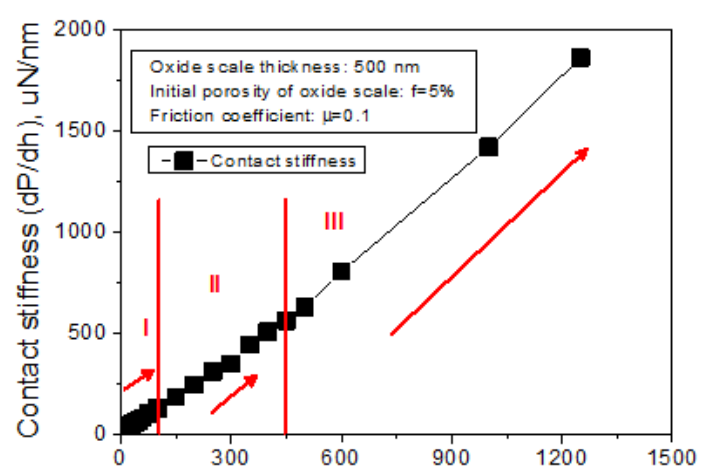

(a) Maximum nanoindentation depth, $\mathrm{nm}$

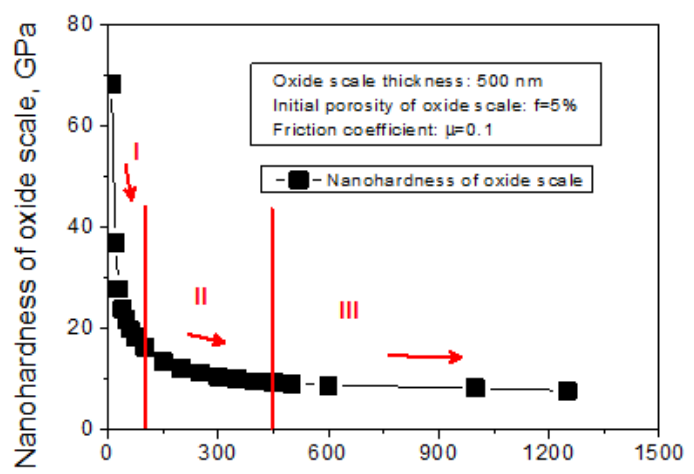

(c) Maximum nanoindentation depth, $\mathrm{nm}$

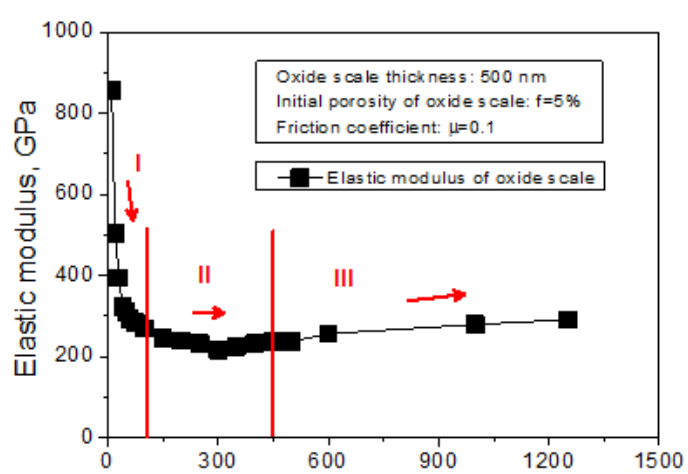

(b) Maximum nanoindentation depth, $\mathrm{nm}$

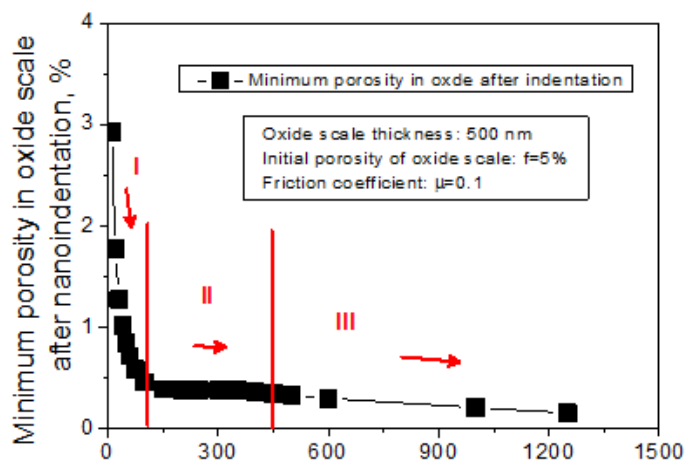

(d) Maximum nanoindentation depth, $\mathrm{nm}$

Fig. 8 Plots of simulated (a) contact stiffness $(d P / d h)$, (b) elastic modulus of oxide scale, (c) nanohardness of oxide scale, and (d) minimum porosity in oxide scale after nanoindentation against the maximum nanoindentation depth.

Based on $P$-h curves in Fig. 6, contact stiffness, elastic modulus and nanohardness have been calculated separately. Fig. 8a shows that contact stiffness increases linearly with the maximum nanoindentation depth and the curve can be divided into three regions depending on the slope. As marked in the figure, region I has the maximum nanoindentation depth less than $150 \mathrm{~nm}$; region II has the maximum nanoindentation depth between $150 \mathrm{~nm}$ and $450 \mathrm{~nm}$; region III has the maximum nanoindentation depth larger than $450 \mathrm{~nm}$. It is obvious that the slope of unloading curves increases gradually from in region I to in region III. When the maximum loading depth reaches to $1250 \mathrm{~nm}$, the contact stiffness rises up to $1866.3 \mathrm{uN} / \mathrm{nm}$.

Fig. $8 \mathrm{~b}$ and $\mathrm{c}$ shows the calculated elastic modulus and nanohardness of the oxide scale using Eqs. (9) and (12), respectively, based on finite element simulations. It is worth noting that these two equations are applied in this study since there are no universe standard equations available for elastic modulus and nanohardness calculations for film/substrate composite materials considering the influence of substrate. It is obvious that both of them decrease dramatically in region I. The corresponding elastic modulus and nanohardness equals 854.8 $\mathrm{GPa}$ and $69.3 \mathrm{GPa}$, respectively, when the maximum nanoindentation depth is $10 \mathrm{~nm}$. When 
the maximum nanoindentation depth changes to $100 \mathrm{~nm}$, elastic modulus and nanohardness decreases quickly to $268.1 \mathrm{GPa}$ and $16.5 \mathrm{GPa}$. It is clear that the reduction reaches to about $68.6 \%$ in elastic modulus and $76.2 \%$ in nanohardness. Such kind of significant changes under very low loads is called size effect, which has already been reported in many studies on nanoindentations of other bulk metallic materials and thin films/coatings [47]. The indentation size effect can be induced by many mechanisms, such as friction, elastic recovery, dislocation processes, material surface energy, plastic flow initiation and even statistical measurement errors [42,43]. According to the previous experimental observations [17], microstructure inhomogeneity within the oxide layer and its surface roughness can also lead to the nanoindentation size effect. In-situ nanoindentation experiment under TEM system is required to gain more understanding about the dislocation processes and deformation initiation of oxide scale as well as the deformation response of HSS substrate.

As can be seen from Fig. $8 \mathrm{~b}$ and c, there are much smaller variations when the maximum nanoindentation depth is beyond $100 \mathrm{~nm}$. In region II, elastic modulus decreases very slightly first and then increases slowly. A minimum elastic modulus of $216.4 \mathrm{GPa}$ is obtained under the peak loading depth of $300 \mathrm{~nm}$. By contrast, there is only a slight monotonic decrease in the nanohardness in this region. According to Fig. 8c, the corresponding nanohardness of oxide scale is about $11.9 \mathrm{GPa}$ and $9.4 \mathrm{GPa}$, respectively, for the maximum nanoindentation depth of $150 \mathrm{~nm}$ and $450 \mathrm{~nm}$. It is obvious that deformation of HSS substrate in region II can retard the nanohardness decrease of oxide scale. In region III, elastic modulus of oxide scale continues rising while its nanohardness keeps decreasing. It should be noted that both of them evolve in a very small rate as shown in the figures. From Fig. $8 \mathrm{~b}$, it is obvious that the corresponding resolved elastic modulus during nanoindentation is always smaller than the elastic modulus of oxide scale, but they have the same evolution tendency with the maximum nanoindentation depth. Fig. $8 \mathrm{~d}$ shows the evolution of the minimum porosity that can be obtained in the oxide scale during nanoindentation as a function of the maximum loading depth, when the initial oxide scale porosity is $5 \%$. From this figure, it has been found that the obtained minimum porosity is about $2.95 \%$ when the maximum loading depth is $10 \mathrm{~nm}$. It decreases quickly to $0.5 \%$ when the maximum loading depth increases up to $100 \mathrm{~nm}$ (in region I). The minimum porosity in the oxide scale maintains at about $0.45 \%$ when the maximum loading depth varies from $150 \mathrm{~nm}$ to $450 \mathrm{~nm}$ (in region II). It decreases gradually with further load during nanoindentation and it reaches to about $0.15 \%$ when the maximum loading depth is $1250 \mathrm{~nm}$ (in region III). 

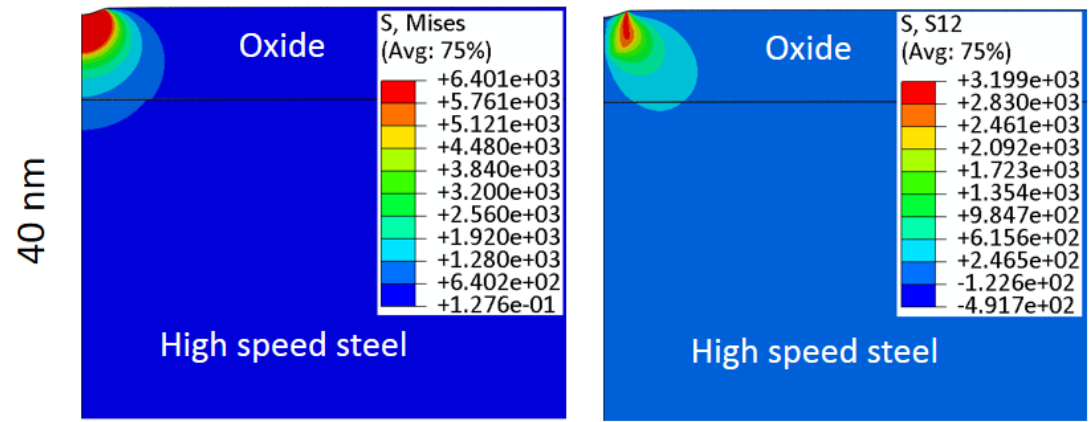

High speed steel
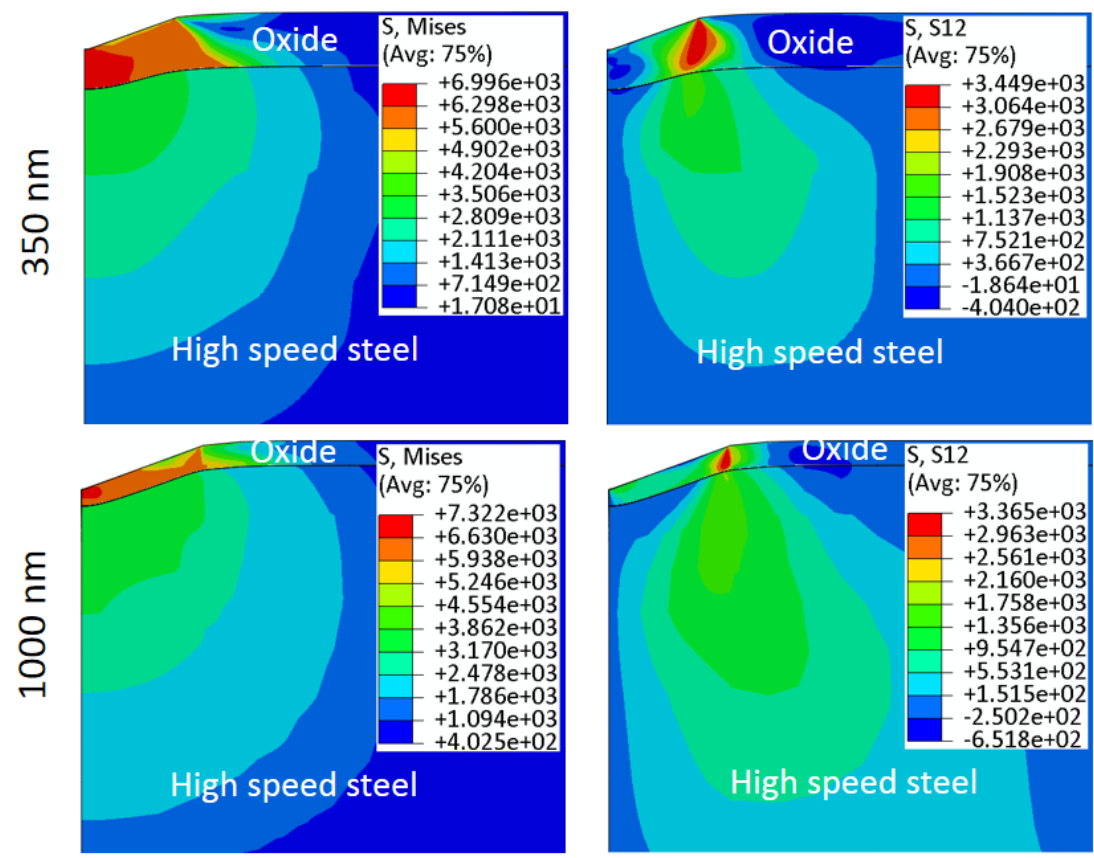

(a)

(b)

Fig. 9 Contours of stress distributions under the peak load during nanoindentation with the maximum loading depths of $40 \mathrm{~nm}, 350 \mathrm{~nm}$ and $1000 \mathrm{~nm}$ : (a) von Mises stress (S), and (b) shear stress (S12).

Fig. 9 and Fig. 10 show the von Mises stress and shear stress distributions in the oxide scale and HSS substrate under the peak load during nanoindentation and after unloading, respectively. In order to understand the effect of nanoindentation depth, three cases located in different regions as defined in Fig. 8 have been compared. From Fig. 9a and Fig. 10a, it has been found that the maximum von Mises stress is about 6400.6 MPa during loading for the maximum nanoindentation depth of $40 \mathrm{~nm}$ (in region I) and decreases to $4983.2 \mathrm{MPa}$ after unloading. In addition to the magnitude, position having the maximum stress also changes. It has moved from below the indent center to the edge of residual indent (or contact boundary) when removing the load. In this case, the stress in HSS substrate is almost zero. However, von Mises stress distribution changes significantly when increasing nanoindentation depth to 350 $\mathrm{nm}$ (in region II) or $1000 \mathrm{~nm}$ (in region III). In Fig. 9a, along vertical direction, the oxide region below indent center is subjected to very large von Mises stress during loading under these 
two maximum nanoindentation depths. Along horizontal direction, von Mises stress in oxide scale is still very large until reaching to the contact boundary, where there is very large stress gradient. On the other hand, HSS substrate has been plastically deformed as well. With increasing the loading depth, the plastic deformation zone increases much quicker along vertical direction than horizontal direction. As can be seen from Fig. 10a, large residual von Mises stress still exists at the oxide-steel interface below the indent boundary after unloading because of deformation in steel matrix. The maximum value is about 5833.1 MPa for loading depth of $350 \mathrm{~nm}$ and $6021.6 \mathrm{MPa}$ for $1000 \mathrm{~nm}$. By contrast, the indent surface has much smaller stress.
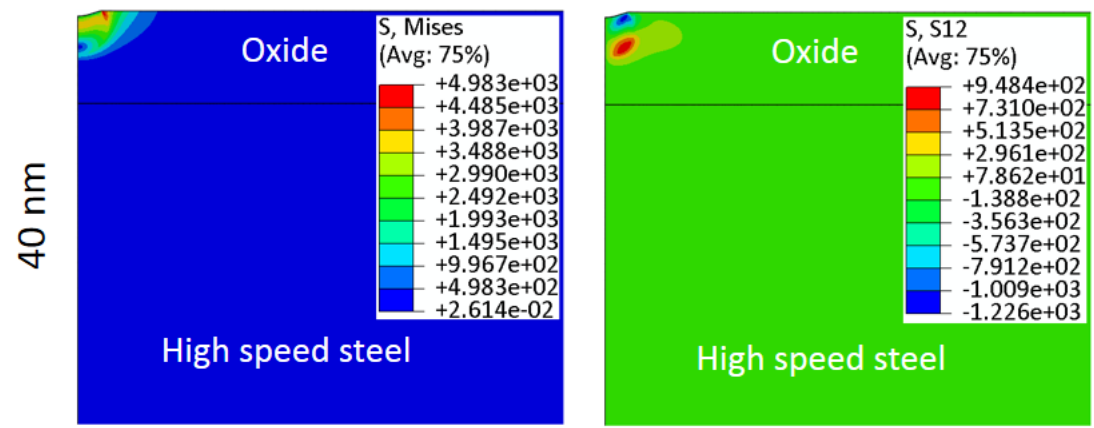

High speed steel
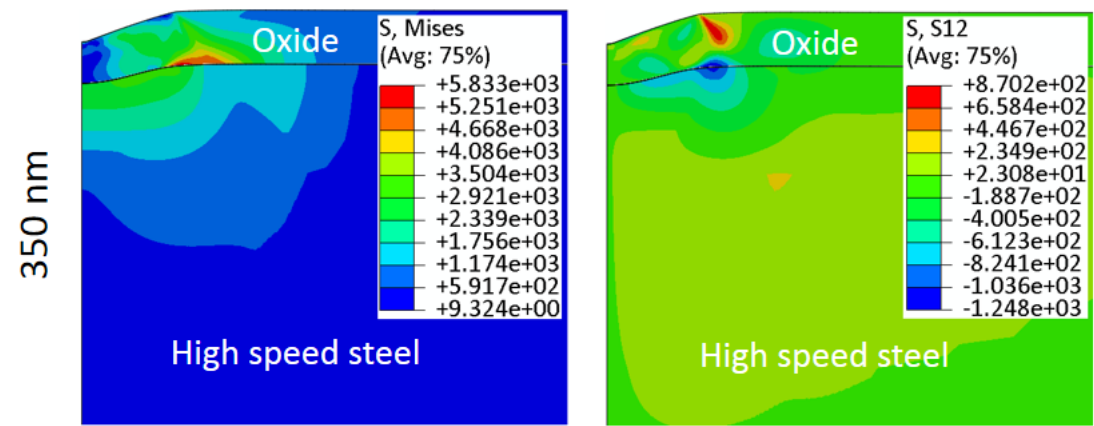

High speed steel

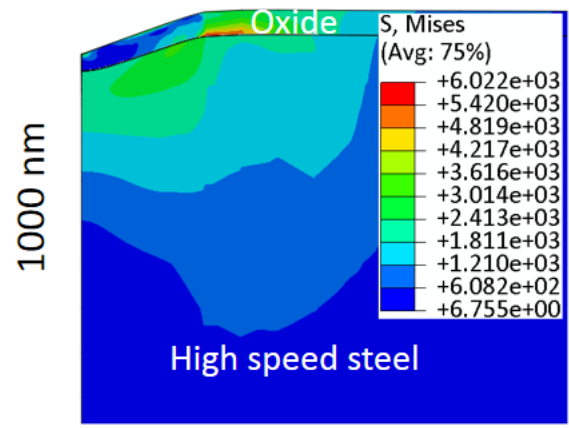

(a)

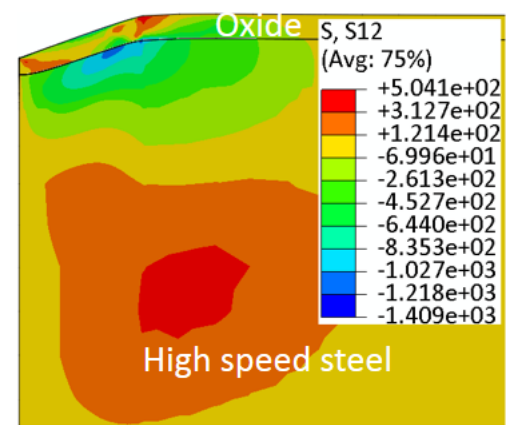

(b)

Fig. 10 Contours of stress distributions after unloading of nanoindentation with the maximum loading depths of $40 \mathrm{~nm}, 350 \mathrm{~nm}$ and $1000 \mathrm{~nm}$ : (a) von Mises stress (S), and (b) shear stress (S12).

The shear stress distributions during loading have been compared in Fig. 9b. The maximum shear stress under loading depth of $40 \mathrm{~nm}$ is about $3199.4 \mathrm{MPa}$, and there is only $5.2 \%$ increment when loading depth changes to $1000 \mathrm{~nm}$. It is interesting to see that shear stress 
in oxide layer always concentrates around the contact boundary and extends downward in a shape of bulb. By comparing these three images in Fig. 9b, it has been found that orientation of the bulb-shaped shear stress contour changes with load during nanoindentation. With increasing the nanoindentation load, there is a slight clock-wise rotation of the bulb-shaped around $\mathrm{Z}$ axis (as indicated in Fig. 3a) towards the indentation center. By comparison, the shear stress in HSS substrate only changes in magnitude and size, but there is no change in shape and orientation. After unloading, as shown in Fig. 10b, the indent boundary undergoes compressive residual shear stress (-1226.1 MPa) for nanoindentation depth of $40 \mathrm{~nm}$. As for $350 \mathrm{~nm}$ and $1000 \mathrm{~nm}$ nanoindentations, positive shear stress exists around the indent boundary but negative shear stress exists at oxide-matrix interface below the indent boundary.

Simulation results reveal that, larger indentation depth results into a higher stress, and oxide scale always has higher stress compared to the soft HSS substrate. In addition, it has been found that deformation of HSS substrate during nanoindentation also changes the stress contours, particularly shear stress contours as displayed in Fig. 9b and Fig. 10b. These results indicate that the deformed oxide scale performs like a large indenter for HSS material when indentation depth is very large. The oxide scale can also be treated as an effective hard protective layer above HSS surface to reduce the plastic deformation during nanoindentation. Besides, Fig. 9 can interpret that indentation becomes easier once HSS substrate starts deformation, which leading to a larger contact area and then decreasing the nanohardness of oxide scale as observed in Fig. 8c.

\subsection{Effect of friction during nanoindentation}

In most of previous modelling studies on nanoindentations $[26,27,44,48]$, the effect of friction in the contact response has been neglected for simplicity. However, according to recent studies $[40,41,49]$, elastic modulus, hardness and crystallographic orientation are found to change with the friction coefficient. In practical hot rolling process, lubricants are always applied, which definitely affects the surface contact conditions among oxides, HSS work roll and strips $[1,21]$. Therefore, a clear understanding about the influence of friction during nanoindentation on the surface of oxidized HSS work roll is very essential. It has been found that no such kind of reports are available based on a careful literature review. To provide a systematic understanding, three nanoindentation depths from different regions as defined in Fig. 8 are studied in this section. For each nanoindentation depth, various friction coefficients have been compared assuming a constant initial porosity of $5 \%$ in oxide scale. 


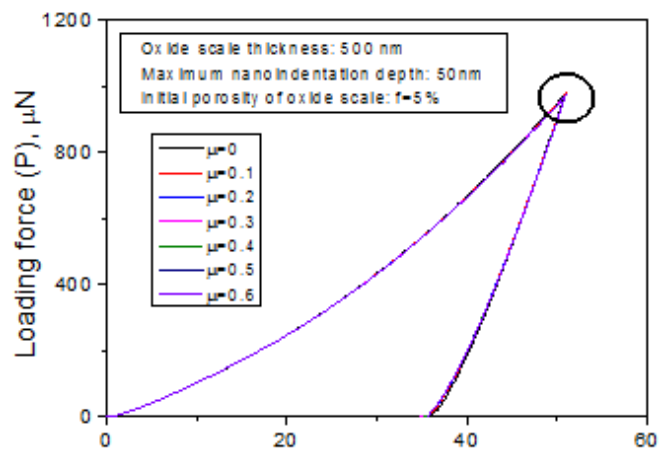

(a) Nanoindentation depth (h), $\mathrm{nm}$

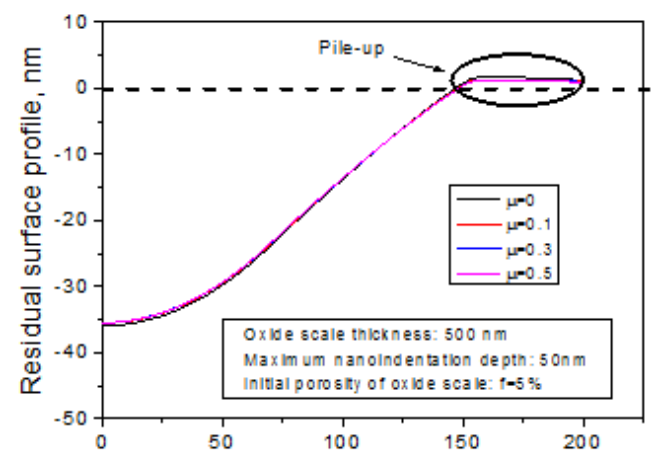

(c) Horizontal distance from center, $\mathrm{nm}$

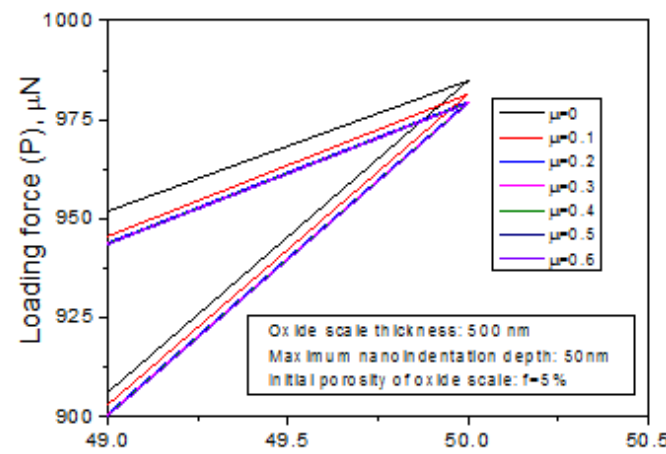

(b) Nanoindentation depth (h), $\mathrm{nm}$

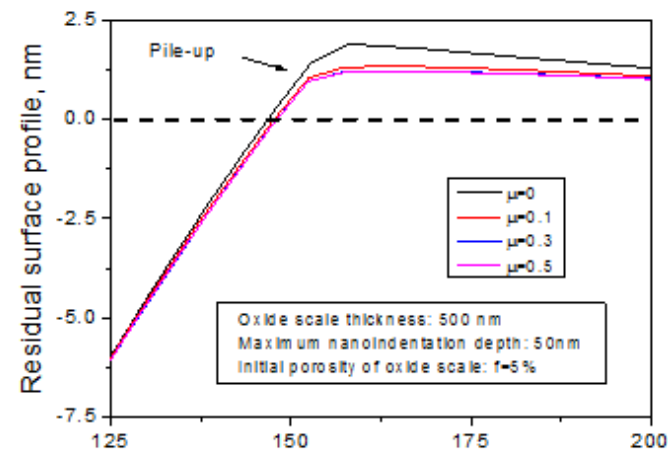

(d) Horizontal distance from center, nm

Fig. 11 (a) The $P$ - $h$ curves under different friction conditions (with friction coefficient of $\mu=0,0.1,0.2$, $0.3,0.4,0.5$ and 0.6 ) with maximum nanoindentation depth of $50 \mathrm{~nm}$, (b) magnified $P$ - $h$ curves for the black circle highlighted region in (a), (c) residual surface profiles in oxide scale under different frictional conditions (with friction coefficient of $\mu=0,0.1,0.3$ and 0.5 ) with maximum nanoindentation depth of $50 \mathrm{~nm}$, (d) magnified surface profiles from the black circle highlighted region in (c), which indicates the pile-up during nanoindentation.

Fig. 11a shows the $P$ - $h$ curves under friction coefficient from 0 to 0.6 when the maximum nanoindentation depth is $50 \mathrm{~nm}$ (located in region I). It is observed that all these curves are quite similar in both shape and magnitude. Fig. $11 \mathrm{~b}$ is the magnification of the circular highlighted part in Fig. 11a, which reveals the differences induced by friction. As can be seen, frictionless contact leads to the greatest loading force of $986.8 \mu \mathrm{N}$. Then the peak load decreases to $981.4 \mu \mathrm{N}$ with increasing the friction coefficient to 0.1 , but the results are almost the same (about $978.1 \mu \mathrm{N}$ ) when friction coefficient is larger than 0.3. Elastic modulus and nanohardness of oxide scales are calculated according to Fig. 11a, and the results indicate a similar tendency to references $[40,49]$. It has been found that the friction coefficient has a positive effect on $\mathrm{E}$ but an opposite effect on $\mathrm{H}$ when the friction coefficient is less than 0.3 . When the friction coefficient is higher than 0.3 , no obvious influence has been seen. 

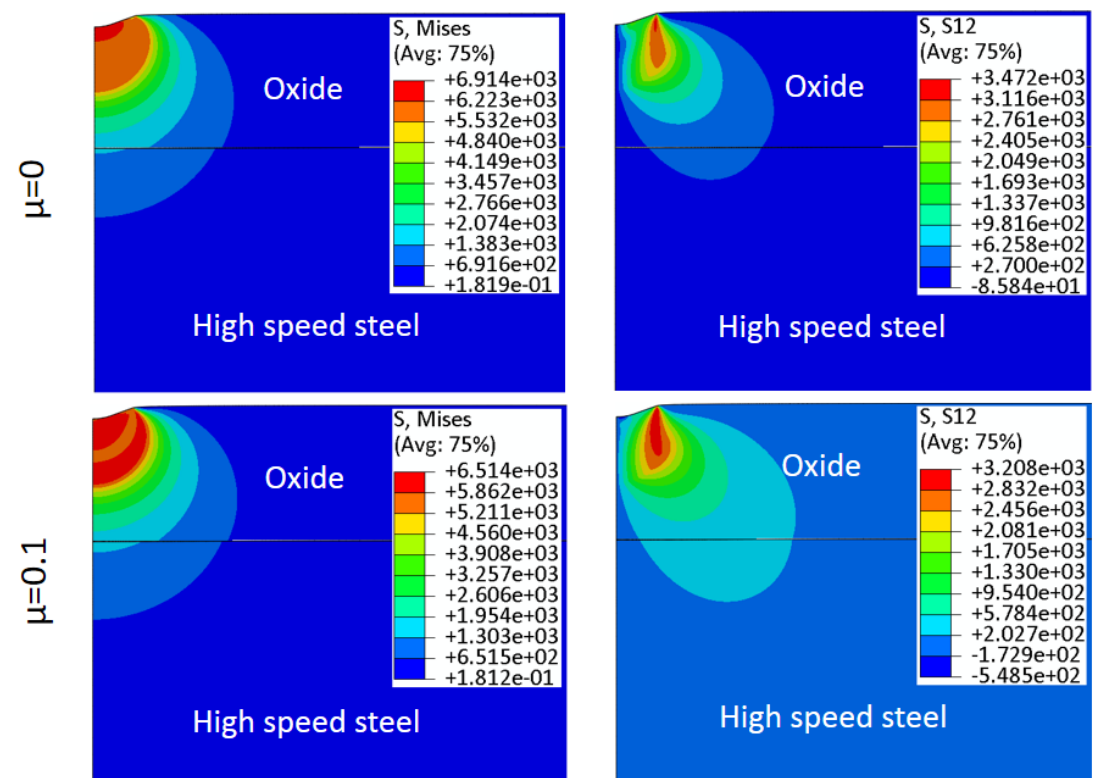

High speed steel

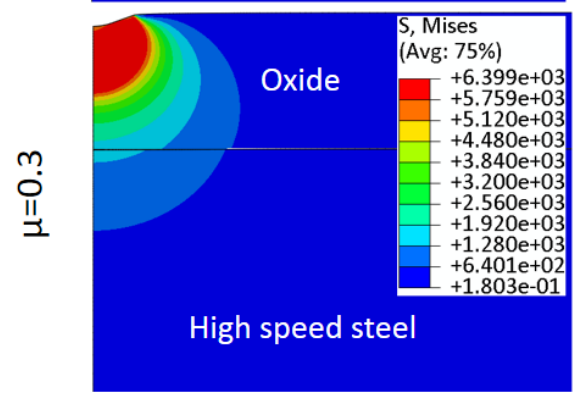

(a)

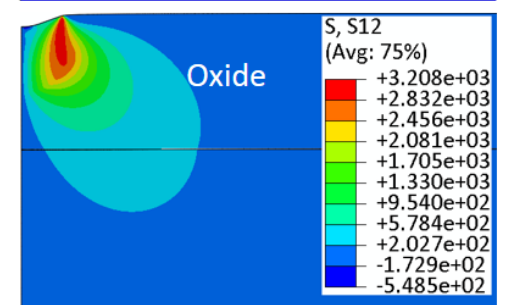

High speed steel

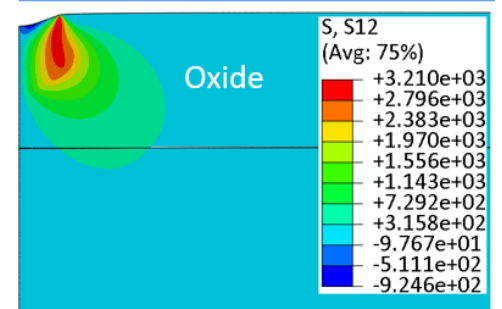

High speed steel

(b)

Fig. 12 Influence of friction ( $\mu=0,0.1$ and 0.3 ) on the contours of stress distributions under the peak load during nanoindentation with the maximum loading depth of $50 \mathrm{~nm}$ : (a) von Mises stress (S), and (b) shear stress (S12).

Fig. 11c shows the influence of friction coefficient on residual surface profile of the indents for the peak nanoindentation depth of $50 \mathrm{~nm}$. It is clear that very similar features are obtained and pile-up occurs at the boundary of the indents under all frictional conditions. When magnifying Fig. 11c, it is then obvious to see the differences as displayed in Fig. $11 \mathrm{~d}$. The maximum pile-up height decreases gradually from $2.1 \mathrm{~nm}$ for $\mu=0$ to $1.3 \mathrm{~nm}$ for $\mu=0.3$, and there is no more changes if $\mu$ keeps increasing. The ratio of the maximum pile-up height over maximum indentation depth is about $4.2 \%$ for $\mu=0$ and $2.6 \%$ for $\mu=0.3$, respectively. Similar observations have also been reported in the simulations of other metallic materials, no matter using elastic-plastic material models [50-52] or crystal plasticity material model [49]. 

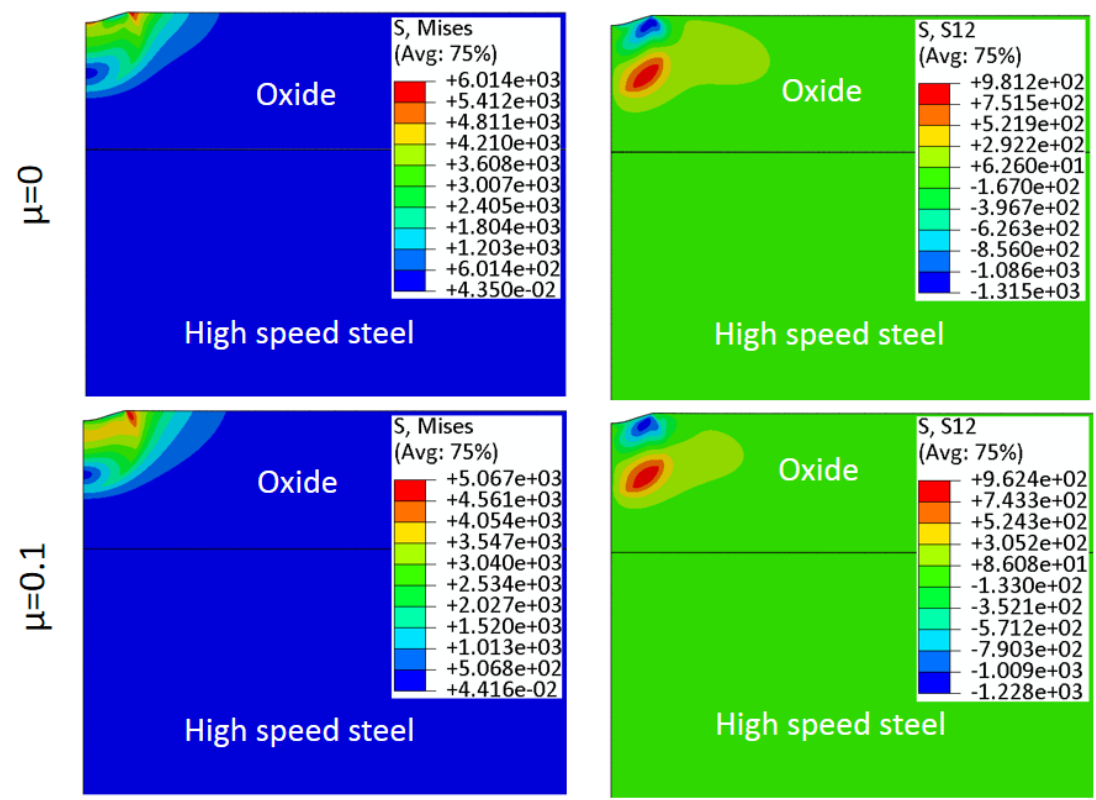

High speed steel

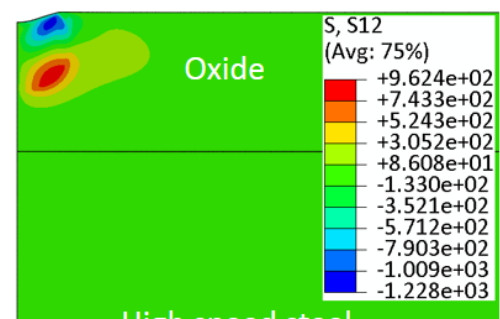

High speed steel

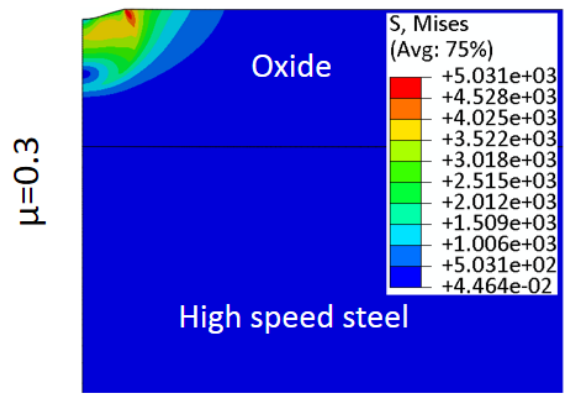

(a)

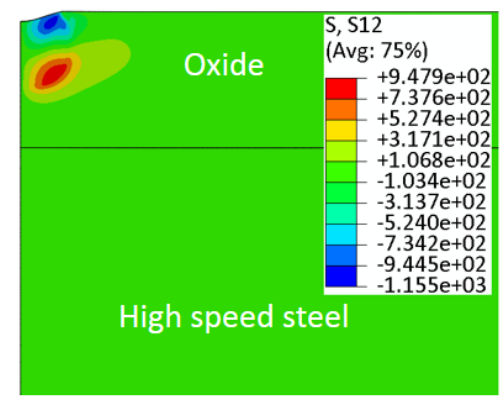

(b)

Fig. 13 Influence of friction ( $\mu=0,0.1$ and 0.3 ) on the contours of stress distributions after unloading of nanoindentation with the maximum depth of $50 \mathrm{~nm}$ : (a) von Mises stress (S), and (b) shear stress (S12).

Influence of friction on distributions of von Mises stress and shear stress is also studied. Fig. 12 and Fig. 13 shows the stress contours for $\mu=0,0.1$ and 0.3 under the peak load during nanoindentation and after unloading, respectively. A comparison in Fig. 12a reveals that friction does not affect shape and size of the plastic deformation zone significantly. Frictionless condition $(\mu=0)$ leads to slightly higher von Mises stress and shear stress, but very small variations exist under the other frictional conditions $(\mu>0)$. The influence of friction mainly occurs at the oxide scale surface during nanoindentation. According to the theoretical analysis [49], friction opposes slip of oxide scale surface and leads to a decrease in the amount of stresses as well as the pile-up (Fig. $11 \mathrm{c}$ and d). It has been found that, the maximum von Mises stress in oxide layer is about 6914.3 MPa for $\mu=0$ and 6399.7 MPa for $\mu=0.3$ during loading, and decreases to about $6014.8 \mathrm{MPa}$ for $\mu=0$ and $5031.2 \mathrm{MPa}$ for $\mu=0.3$ after unloading. 

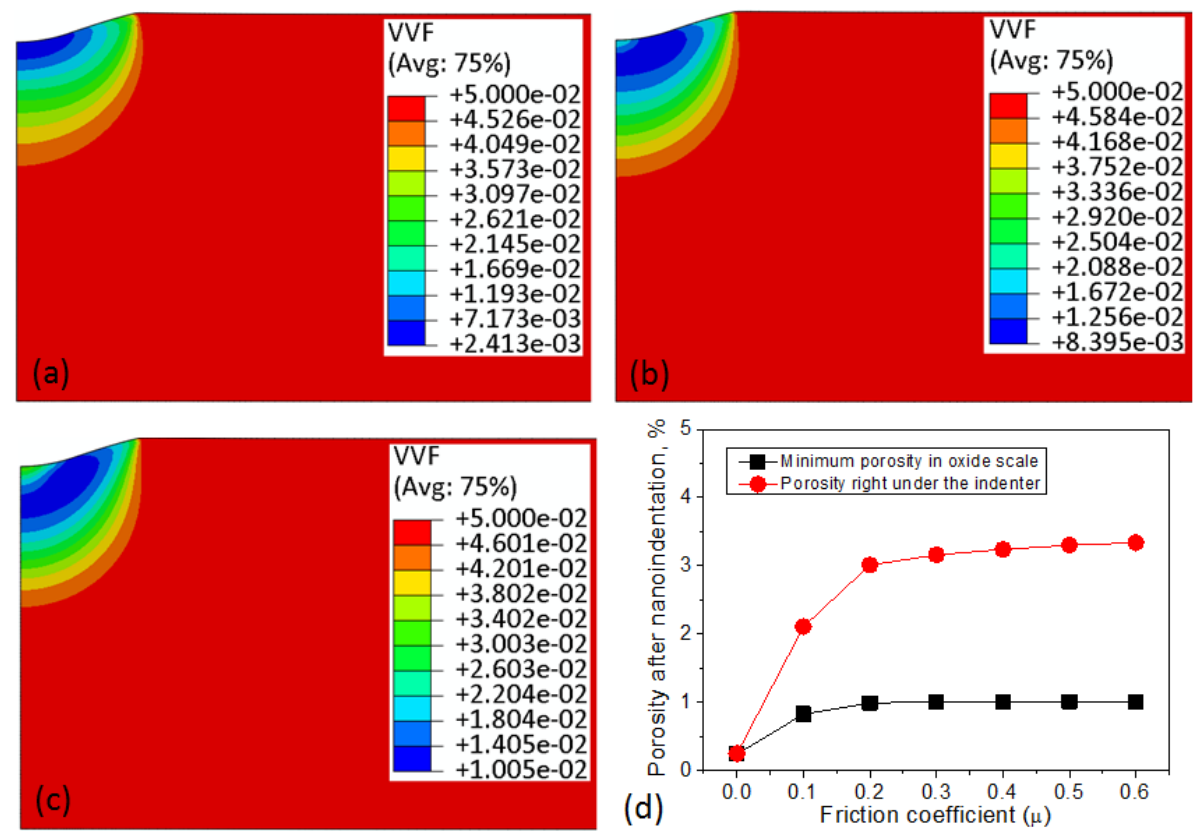

Fig. 14 Influence of frictional condition during nanoindentation on the porosity evolution in the oxide scale with maximum indentation depth of $50 \mathrm{~nm}$. Distribution contour of porosity in oxide scale under friction coefficient of (a) $\mu=0$, (b) $\mu=0.1$ and (c) $\mu=0.3$. (d) The minimum porosity in the oxide scale and the porosity at the position right under the indenter center after nanoindentation with friction coefficient $\mu$ varying from 0 to 0.6 .

Fig. 14 shows the nanoindentation induced porosity changes in oxide scale with the maximum depth of $50 \mathrm{~nm}$ for different friction coefficients. As can be seen from Fig. 14a, for frictionless contact, porosity increases gradually from the indent center along both the horizontal and vertical directions. The oxide scale under the indenter is effectively densified. Fig. 14b and c shows the oxide scale porosity distributions for friction coefficient of 0.1 and 0.3 , respectively. Except the similar vertical and horizontal changes to Fig 14a, there is a common feature that porosity at indent center is slightly larger than its surroundings which has not been seen in Fig. 14a. This should be attributed to the frictional contact with indenter curvature. This area increases with friction coefficient up to 0.3 and then there is no more obvious variation. Fig. $14 \mathrm{~d}$ summarizes the minimum porosity in oxide scale as well as the porosity in the indent center for all contact conditions from $\mu=0$ to 0.6 , calculated using the Eqs. (14)-(17) as introduced in Section 2.2. It is obvious that both of them increase with friction coefficient from $\mu=0$ to 0.3 , and friction coefficients larger than 0.3 lead almost the same results. As can be seen from the figure, the porosity at the position right under the indenter center is not the minimum porosity in the oxide scale. This might be attributed to the geometry of the simulated Berkovich indenter. According to the previous experiments $[17,48]$, it is not practical to have the perfectly sharp Berkovich indenters but they always have small radius. The imperfect indenter tip with curvature surface leads to the decrease of stress 
concentration during nanoindentation right below it, which in turn reduces the densitification of oxide scale porosity. Therefore, the minimum porosity in oxide scale is always lower than the porosity at indent center as shown in Fig. 14d. The difference rises quickly with $\mu$ when it is less than 0.3 and then maintains to about $2.5 \%$ with further changing the friction coefficient.

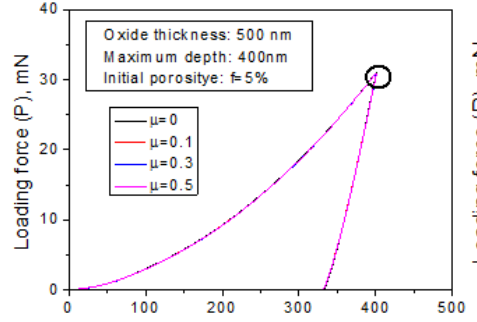

(a) Nanoindentation depth (h), $\mathrm{nm}$

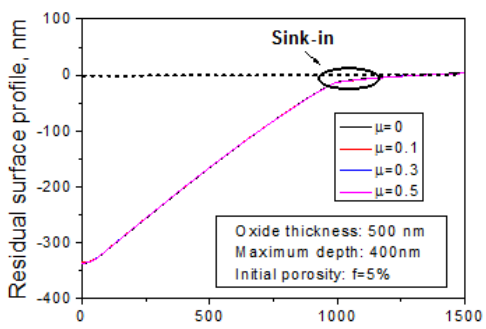

(d) Horizontal distance from center, nm

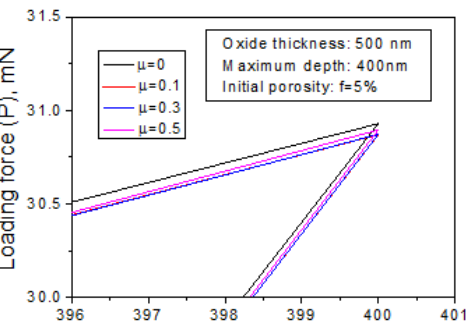

(b) Nanoindentation depth (h), nm

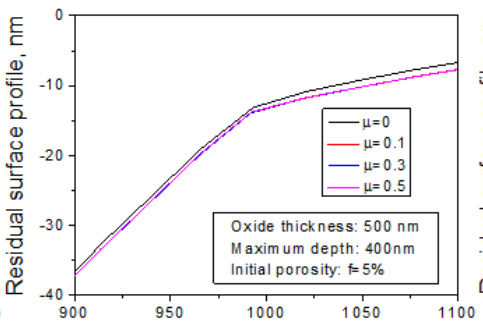

(e) Horizontal distance from center, $\mathrm{nm}$

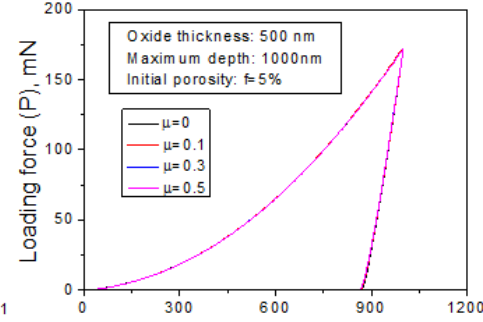

(c) Nanoindentation depth (h), $\mathrm{nm}$

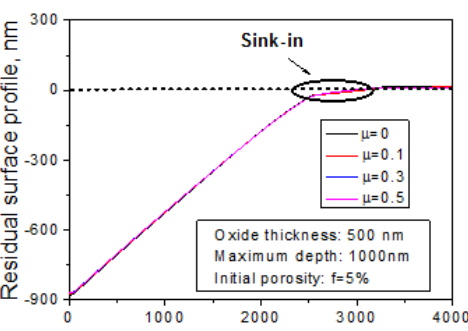

(f) Horizontal distance from center, $\mathrm{nm}$

Fig. 15 Effect of friction on $P$-h curves during nanoindentation with the maximum loading depth of (a) $400 \mathrm{~nm}$, (b) $400 \mathrm{~nm}$ (highlighted region in (a)), and (c) $1000 \mathrm{~nm}$. Effect of friction on residual surface profiles in oxide scales during nanoindentation with the maximum loading depth of (d) $400 \mathrm{~nm}$, (e) 400 $\mathrm{nm}$ (highlighted region in (d)), and (f) $1000 \mathrm{~nm}$.

In addition to region I, effect of friction during nanoindentations in region II and III have also been examined. Fig. 15a shows the $P$ - $h$ curves for maximum nanoindentation depth of 400 $\mathrm{nm}$ (located in region II) with friction coefficients of $0,0.1,0.3$ and 0.5 . Similar to the results in Fig. 11, a higher peak loading force can be seen under a lower friction coefficient from the magnified curves in Fig. 15b. The difference among them is very small. The peak loading force is about $30.93 \mathrm{mN}$ for $\mu=0$ and about $30.86 \mathrm{mN}$ for $\mu=0.5$, respectively. When the maximum nanoindentation depth increases up to $1000 \mathrm{~nm}$ (located in region III), very close results are obtained and effect of friction can be neglected as shown in Fig. 15c. Therefore, it can be concluded that friction has a negative influence on the load-depth curves for a given oxide scale (with constant oxide scale thickness and porosity) irrespective of nanoindentation depths, but the influence is small.

Residual surface profiles after nanoindentations with $400 \mathrm{~nm}$ reveal formation of sink-ins around the indenter contact boundary for all friction coefficients in Fig. 15d. The magnified profiles in Fig. 15e suggest that $\mu=0$ leads to a slight amount of sink-in than the other friction 
coefficients. Very similar results have also been obtained in Fig. 15f, for the maximum nanoindentation depth of $1000 \mathrm{~nm}$. Formation of sink-ins during nanoindentation under large loads can also be found from the microscopy observations as shown in Fig. 4. It should be noted that the present model is not able to simulate development of micro-cracks which have been marked in Fig. 4c. By comparing the results in Fig. 11 and Fig. 15, it is able to see that pile-up develops in region I while sink-in develops in region II and III during nanoindentations on the surface of the oxidized HSS material. In addition, this is the first time to report that friction has the negative effect on the amount of pile-ups but a positive effect on sink-ins depending on the nanoindentation depth.

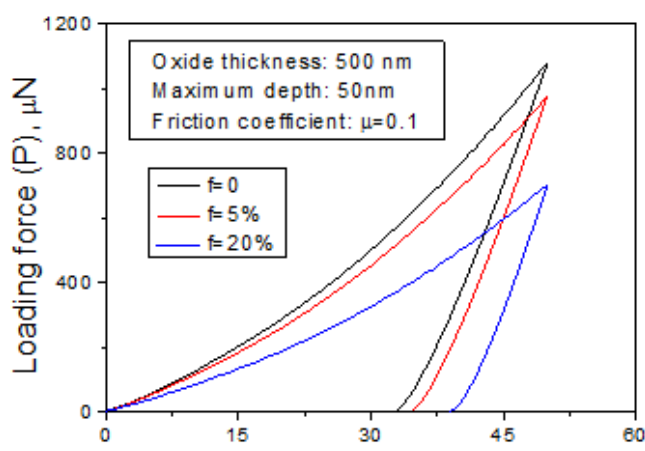

(a) Nanoindentation depth (h), nm

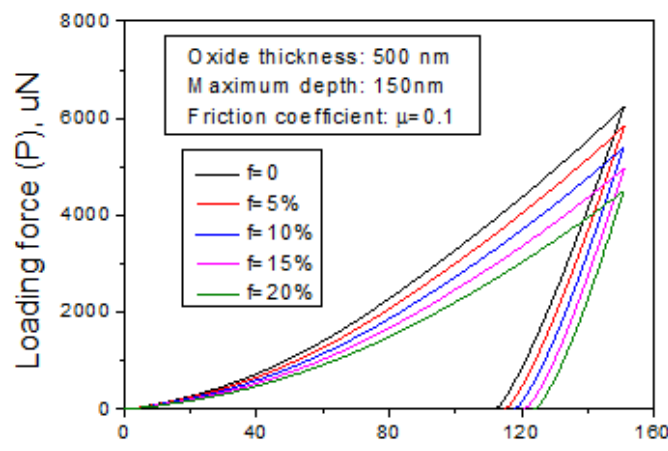

(b) Nanoindentation depth (h), $\mathrm{nm}$

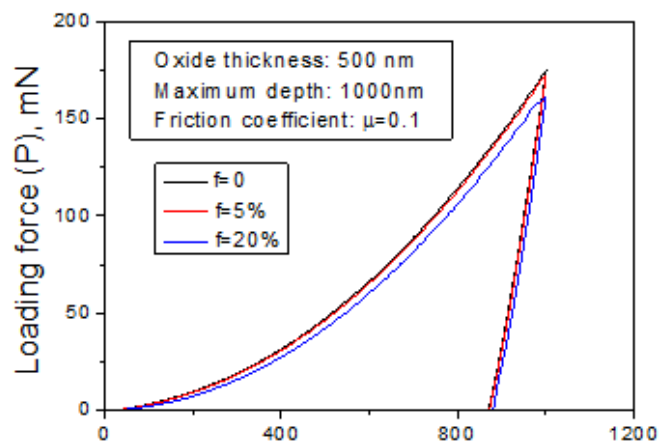

(c) Nanoindentation depth $(\mathrm{h}), \mathrm{nm}$

Fig. 16 Effect of initial porosity in oxide scale on $P$ - $h$ curves during nanoindentation with the maximum loading depth of (a) $50 \mathrm{~nm}$, (b) $400 \mathrm{~nm}$, and (c) $1000 \mathrm{~nm}$.

\subsection{Effect of porosity in oxide scale}

This section focuses on studying the effect of initial porosity in the oxide scales during nanoindentation, by selecting three maximum nanoindentation depths in region I, II, and III, as defined in Fig. 8, respectively. In order to avoid the effect of friction, all simulations were conducted with a constant friction coefficient of $\mu=0.1$. 


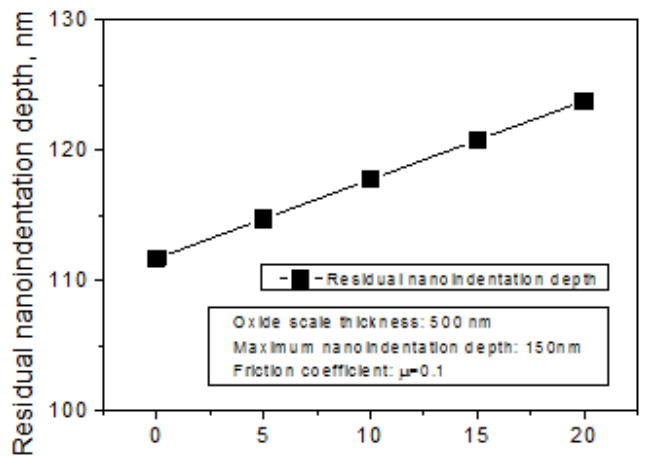

(a) Initial porosity of oxide scale, \%

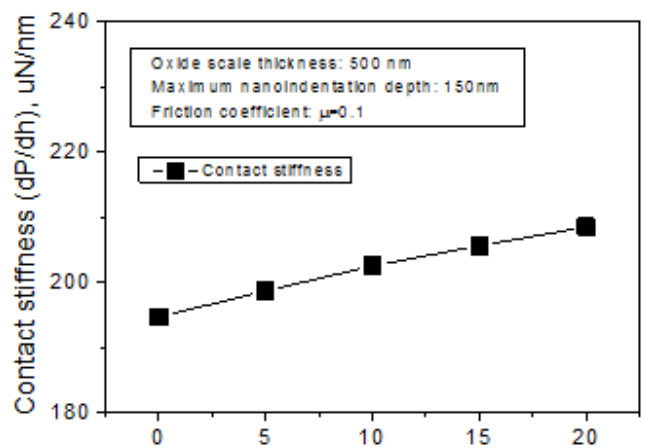

(c) Initial porosity of oxide scale, \%

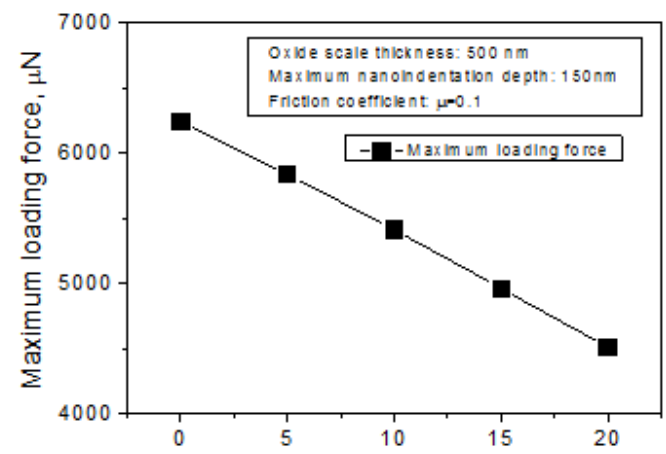

(b) Initial porosity of oxide scale, \%

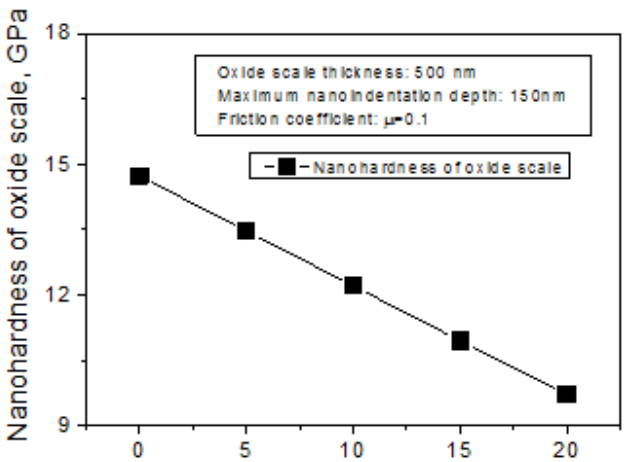

(d) Initial porosity of oxide scale, \%

Fig. 17 Effect of initial porosity in oxide scale on (a) residual indentation depth, (b) maximum loading force, (c) contact stiffness, and (d) nanohardness of oxide scale during nanoindentation with the maximum loading depth of $150 \mathrm{~nm}$.

Fig. 16 shows a comparison of $P$ - $h$ curves for different oxide scale porosities from 0 to $20 \%$. From these curves, it is obvious that porosity has the similar influence irrespective of nanoindentation depths. Under all three studied nanoindentation depths, the peak loading force decreases gradually with increasing the oxide scale porosity, but the residual indentation depth changes oppositely. Therefore, it is reasonable to only select one nanoindentation depth for further discussions. Based on calculations from Fig. 16b, evolutions of residual indentation depth, peak loading force, contact stiffness as well as nanohardness, have been plotted in Fig. 17 as a function of the original porosity in oxide scale. As can be seen, there is very good linear relationship between residual depth and initial porosity. When the oxide scale is fully dense without any pores or voids, the residual depth is smallest and it is about $111.7 \mathrm{~nm}$. With increasing porosity up to $20 \%$, residual depth rises to about $123.8 \mathrm{~nm}$ with a $10.83 \%$ increment. Similar evolution tendency is also seen in Fig. 17c for contact stiffness, where porosity of $20 \%$ leads to the maximum contact stiffness of about $208.5 \mu \mathrm{N} / \mathrm{nm}$. On the other hand, both the peak loading force and nanohardness decrease with oxide layer porosity as shown in Fig. $17 \mathrm{~b}$ and d. It is obvious that increasing the porosity from 0 to $20 \%$ results in about $27.76 \%$ reduction in peak load and $34.01 \%$ reduction in nanohardness, respectively. By 
contrast, the effect of porosity on elastic modulus is very slight and there is only a small variation. These observations are consistent with recent studies on polymer films [53] and porous ceramics [54]. As suggested by Chen et al. [48], such a slight influence of porosity should be due to the small densified zone in oxide scale compared to the longer range of elastic deformation around the nanoindentation.

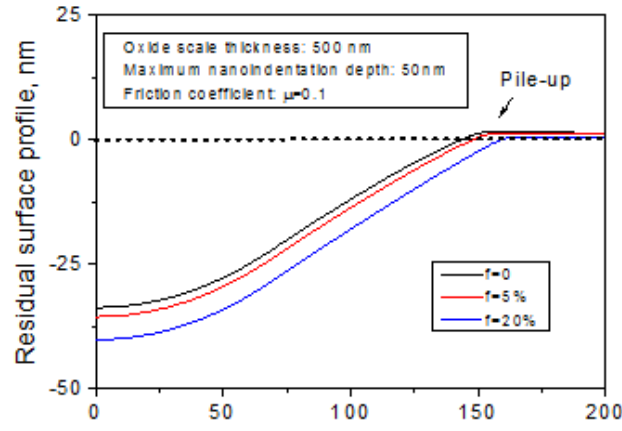

(a) Horizontal distance from center, $\mathrm{nm}$

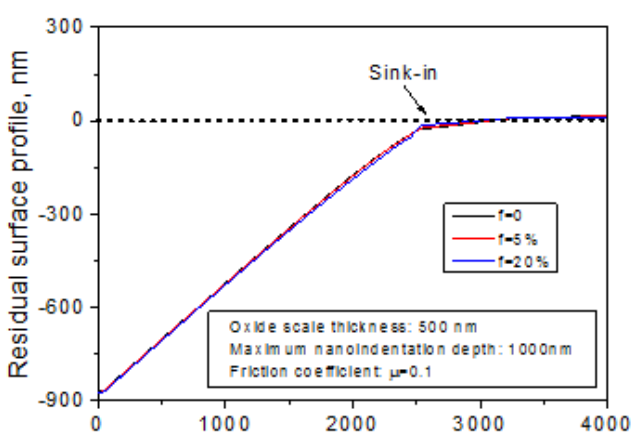

(c) Horizontal distance from center, $\mathrm{nm}$

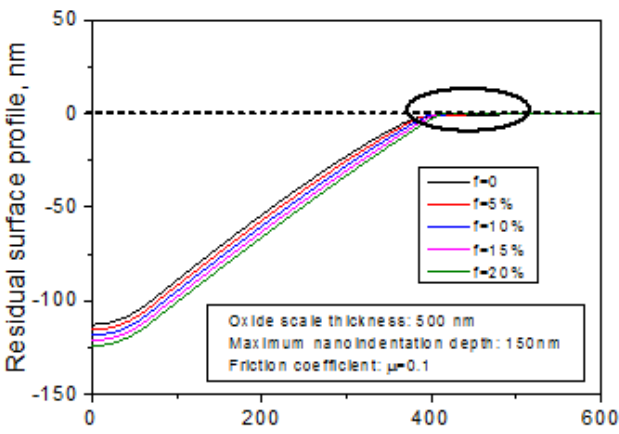

(b) Horizontal distance from center, nm

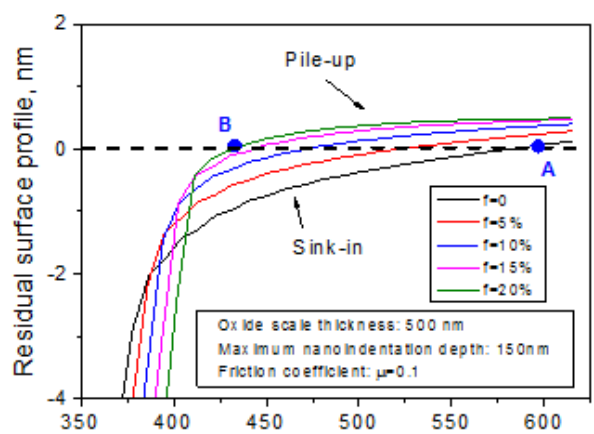

(d) Horizontal distance from center, $\mathrm{nm}$

Fig. 18 Effect of initial porosity in oxide scale on residual surface profile after nanoindentation with the maximum nanoindentation depth of (a) $50 \mathrm{~nm}$, (b) $150 \mathrm{~nm}$, and (c) $1000 \mathrm{~nm}$. (d) Enlarged region shown in (b).

Effect of initial porosity on the residual surface profile of oxide scale is also investigated. It is very interesting to find that all porosities lead to development of pile-up around the contact boundary as marked in Fig. 18a for the nanoindentation depth of $50 \mathrm{~nm}$. By contrast, sink-in always forms under the nanoindentation depth of $1000 \mathrm{~nm}$ as displayed in Fig. 18c. These two figures also reveal the decreases in the amount of pile-ups or sink-ins with increasing the porosity, respectively. Fig. 18b shows the evolution of indent profile in oxide scale against its initial porosity under nanoindentation with $150 \mathrm{~nm}$. The profiles around contact boundary are not as clear as the other two nanoindentation depths. This is because nanoindentation depth of $150 \mathrm{~nm}$ is very close to the boundary between regions I and II as shown in Fig. 8. The circular highlighted boundary in Fig. 18b is enlarged as shown in Fig. 18d, which obviously reveals a transition of forming pile-up from sink-in with increasing porosity. Points $A$ and $B$ in the figure 
means the intersecting position of deformed oxide scale surface with the original surface height for porosity of 0 and $20 \%$, respectively. From Fig. 18 , it is able to gain a systematic understanding that, the pile-up evolves gradually into the sink-in at oxide scale surface with increasing nanoindentation depth for a given porosity, and amount of pile-up or sink-in decreases gradually with porosity for a given nanoindentation depth.
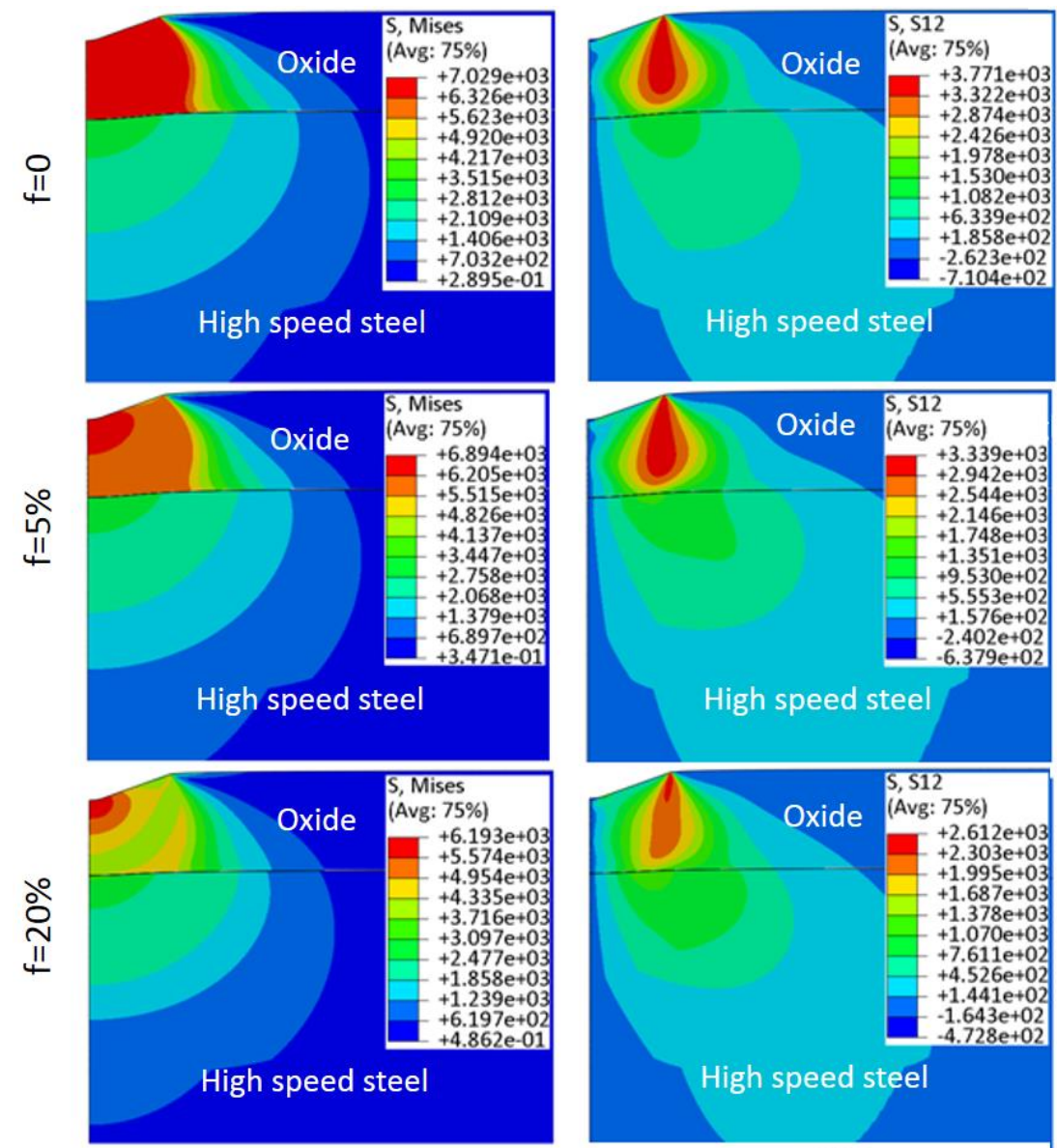

High speed steel
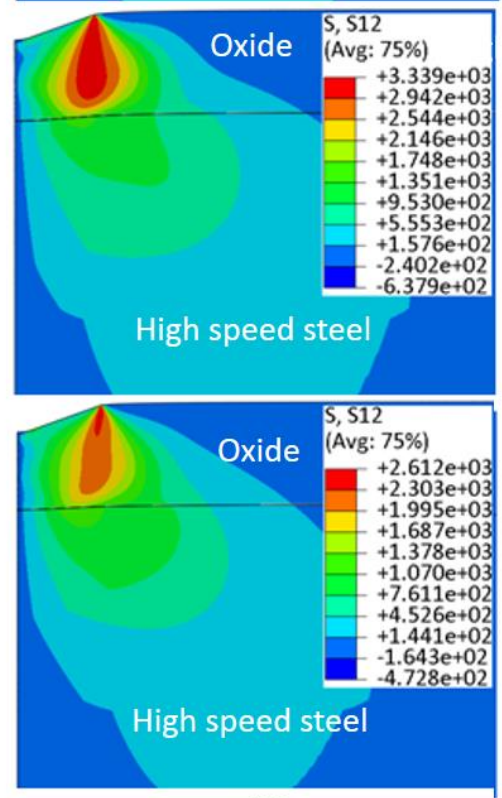

(a)

(b)

Fig. 19 Influence of initial porosity of the oxide scale $(f=0,5 \%$ and $20 \%)$ on the contours of stress distributions under the peak load during nanoindentation with the maximum loading depth of $150 \mathrm{~nm}$ : (a) von Mises stress (S), and (b) shear stress (S12). 


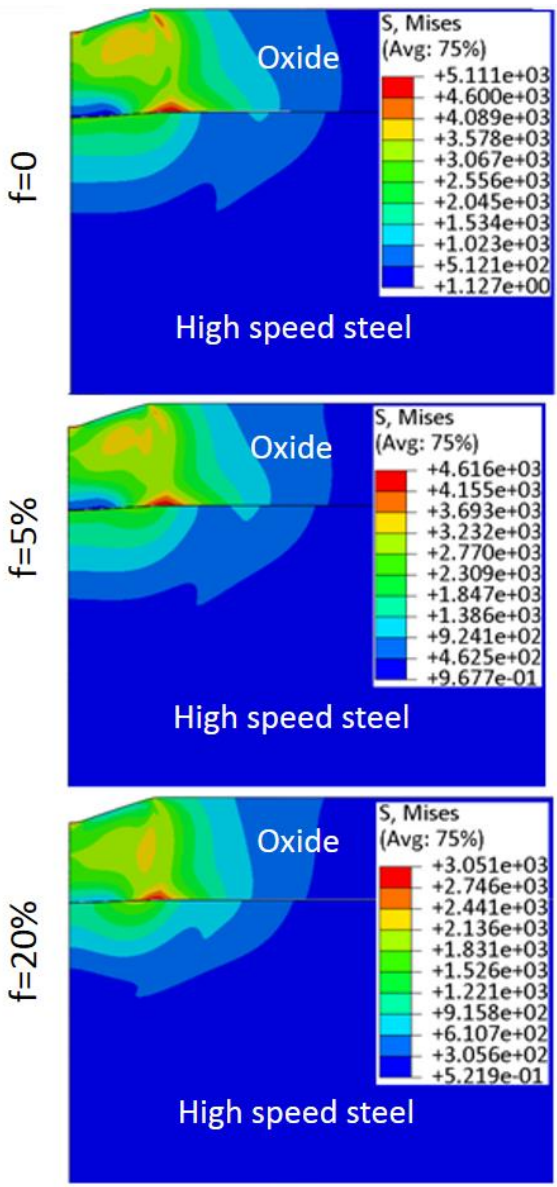

(a)

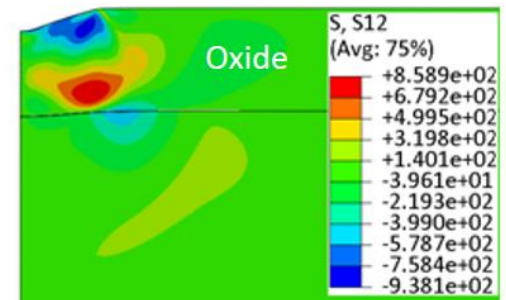

High speed steel

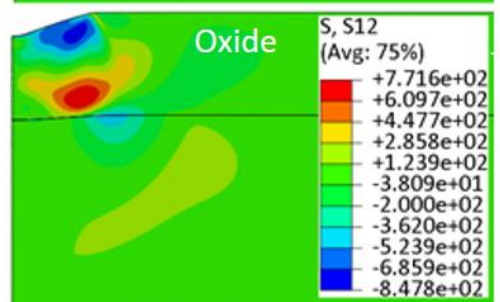

High speed steel

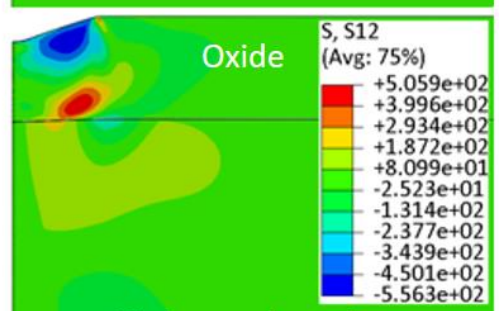

High speed steel

(b)

Fig. 20 Influence of initial porosity of the oxide scale $(f=0,5 \%$ and $20 \%)$ on the contours of stress distributions after unloading of nanoindentation with the maximum depth of $150 \mathrm{~nm}$ : (a) von Mises stress (S), and (b) shear stress (S12).

Fig. 19 and Fig. 20, respectively, shows the effect of initial porosity of oxide scales on stress distributions under the peak load during nanoindentation and after unloading. As shown in Fig. 19a, the maximum von Mises stress under peak load decreases gradually from 7029.5 MPa for initial porosity of 0 to $6193.8 \mathrm{MPa}$ for initial porosity of $20 \%$. The decrement reaches to $11.89 \%$. The figures also suggest that there is a larger area with stress concentrations below the indenter center for a lower porosity. In addition, the stress gradient increases along both horizontal and vertical directions with initial porosity. Similar tendency can be observed in the shear stress filed (Fig. 19b), where shear stress concentrates around the contact boundary and evolves downwards. After unloading as shown in Fig. 20a and b, stress concentrations around the interface between oxide scale and HSS substrate right below the indent boundary are visible. It is evident that HSS substrate undergoes smaller stress with increasing the oxide scale porosity. Therefore, the porous oxide layer can be considered as an effective protective 
media on work roll surface during practical hot rolling to buffer indentation shocks by very hard materials such as flaked carbides [23-25].
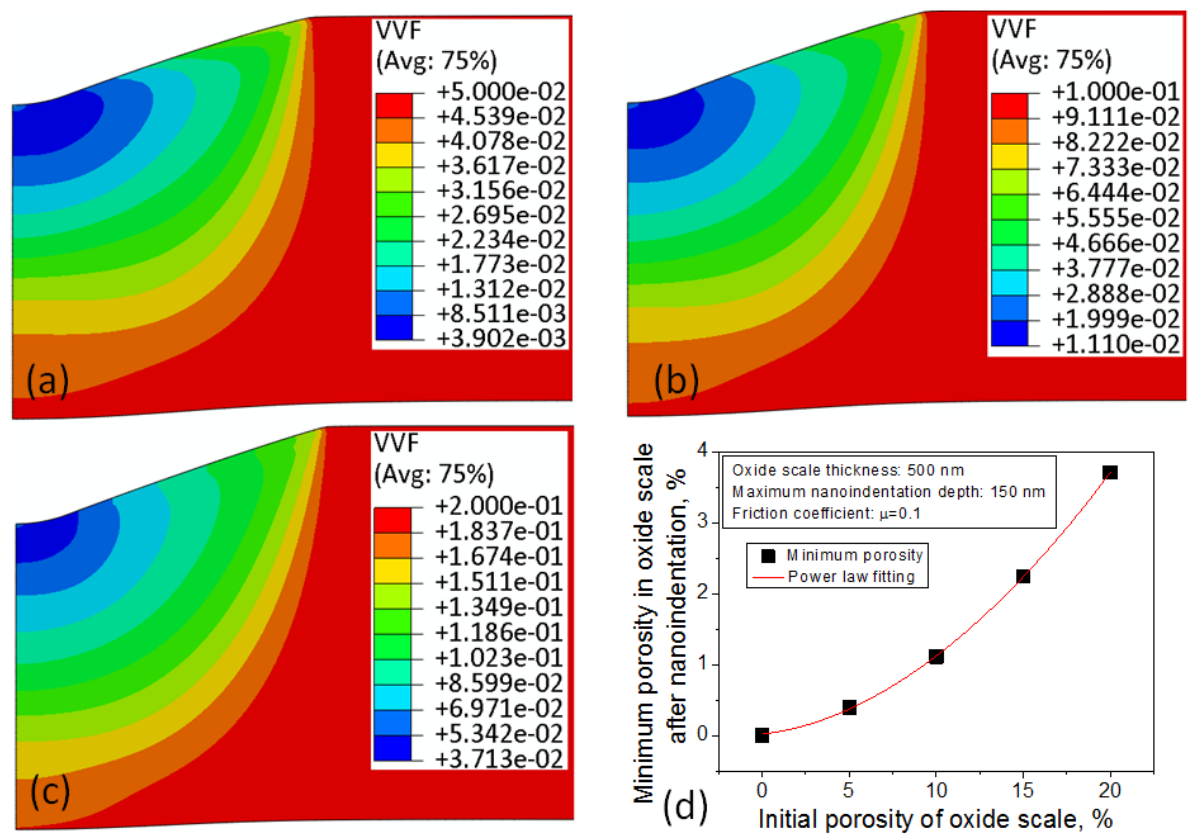

Fig. 21 Contours of porosity in oxide scale during nanoindentation with the maximum loading depth of $50 \mathrm{~nm}$, with initial porosity of (a) $5 \%$, (b) $10 \%$, and (c) $20 \%$. (d) Evolution of the minimum porosity in oxide scale against its initial porosity before nanoindentation.

In Fig. 21a-c, nanoindentation induced porosity changes in oxide scales with initial porosity of $5 \%, 10 \%$ and $20 \%$ have been displayed, respectively. All these contour maps reveal that the region below the indent center has been effectively densified, and the porosity increases gradually along both the horizontal and vertical directions. Such kinds of phenomena have also been observed in some other porous materials $[48,54,55]$. The minimum porosity obtained in oxide scales is summarized in Fig. $21 \mathrm{~d}$. As can be seen, for a given nanoindentation depth of $150 \mathrm{~nm}$, there is a significant effect and the minimum porosity in oxide scale increases quickly with its initial porosity. Their relationship can be mathematically described using the following equation,

$$
f_{\min }=11.45 \times 10^{-3}\left(f_{0}+1.315\right)^{1.889}
$$

where $f_{\min }$ indicates the minimum porosity in the oxide scale after nanoindentation, and $f_{0}$ indicates the initial porosity before nanoindentation.

According to the results shown in this section, the deformation behaviour of oxide scale during nanoindentation can be significantly affected by its porosity, which depends on the substrate material property, oxidation duration, temperature, atmosphere pressure as well as humidity 
[15,17-19]. It is worth noting that the current report only focus on the oxide scale porosity of $\leq 20 \%$. In future, nanoindentation for a wider range of oxide scale porosity will be considered and the relationship between the oxide scale porosity evolution and oxidation parameters will also be examined.

\section{Conclusions}

Nanoindentations on the surface of an oxidized high speed steel work roll material was systematically investigated based on both experimental measurements and finite element simulations. For the first time, effects of nanoindentation depth, friction and initial porosity of oxide scale on the oxidized HSS material have been examined, and the following conclusions can be drawn:

(1) Isothermal oxidation experiment of a high speed steel material was conducted at $600^{\circ} \mathrm{C}$ in a dry atmosphere, leading to the oxide scale having an average thickness of about 517 $\mathrm{nm}$ with an overall porosity of about $4.8 \%$. According to SEM observations on the oxide scale surface after nanoindentation tests, it has been found that both the geometry shape and size of residual indents were greatly affected by the load. Besides, micro-cracks were developed at oxide scale surface when the nanoindentation load was as high as $200 \mathrm{mN}$.

(2) A finite element model considering the practical microstructural features of oxide scale was developed. Good agreement between experiments and simulations suggest that the developed model is reliable to investigate nanoindentation behaviour of the oxidized HSS material.

(3) A significant nanoindentation size effect was observed and three regions can be distinguished as a function of nanoindentation depth. It has been found that, plastic deformation mainly happened in oxide layer when nanoindentation depth was less than $150 \mathrm{~nm}$ (region I), while HSS substrate was plastically deformed together with oxide scale when nanoindentation depth was between $150 \mathrm{~nm}$ and $450 \mathrm{~nm}$ (region II), and HSS substrate was severely deformed when nanoindentation depth was greater than $450 \mathrm{~nm}$ (region III).

(4) In this study, a slight influence of friction was found when friction coefficient was less than 0.3 while almost the same result were obtained for friction coefficients larger than 0.3. By contrast, the initial porosity of oxide scale had a great effect during nanoindentation. For a constant nanoindentation depth, the maximum loading force decreased with increasing 
porosity, while a clear increase in residual indentation depth after unloading was observed.

\section{Acknowledgements}

This work was supported by the Australian Research Council with Grant Nos. DP130103973 and DE180100124, and the Baosteel-Australia Joint Research and Development Centre under Grant Number BA12045. Simulations were conducted using a HPC cluster belongs to University of Wollongong. Dr. Deng would like to acknowledge Dr. Buyung Kosasih for his kind training on nanoindentation tests.

\section{References}

[1] W.L. Roberts, Hot rolling of steels, Marcel Dekker, New York, 1983.

[2] K. Hu, Y. Xia, F. Zhu, N.A. Noda, Evaluation of thermal breakage in bimetallic work roll considering heat treated residual stress combined with thermal stress during hot rolling, Steel Res Int 89 (2018) 201700368.

[3] G.Y. Deng, H.T. Zhu, A.K. Tieu, Q. Zhu, L.H. Su, M. Reid, P.T. Wei, L. Zhang, H. Wang, J. Zhang, J.T. Li, T.D. Ta, Q. Wu, Numerical evaluation of a high speed steel work roll during hot strip rolling process, Mater Sci Forum 904 (2017) 55-60.

[4] C.S. Li, H.L. Yu, G.Y. Deng, X.H. Liu, G.D. Wang, Numerical simulation of temperature field and thermal stress field of work roll during hot strip rolling. J Iron Steel Res Int 14 (2007) 1821.

[5] G.Y. Deng, Q. Zhu, K. Tieu, H.T. Zhu, M. Reid, A.A. Saleh, L.H. Su, T.D. Ta, J. Zhang, C. Lu, Q. $\mathrm{Wu}, \mathrm{D}$. L. Sun, Evolution of microstructure, temperature and stress in a high speed steel work roll during hot rolling: Experiment and modelling, J Mater Process Technol 240 (2017) 200208.

[6] G.Y. Deng, H.T. Zhu, K. Tieu, L.H. Su, M. Reid, L. Zhang, P.T. Wei, X. Zhao, H. Wang, J. Zhang, J.T. Li, T.D. Ta, Q. Zhu, C. Kong, Q. Wu, Theoretical and experimental investigation of thermal and oxidation behaviours of a high speed steel work roll during hot rolling, Int J Mech Sci 131132 (2017) 811-826.

[7] H.H. Kim, J.W. Lim, J.J. Lee, Oxidation behaviour of high speed steels in dry and wet atmospheres, ISIJ Int 43 (2003) 1983-1988.

[8] L. Xu, J. Xing, S. Wei, Y. Zhang, R. Long, Investigation on wear behaviours of high-vanadium high speed steel compared with high-chromium cast iron under rolling contact condition. Mater Sci Eng A 434 (2006) 63-70.

[9] J.H. Lee, J.C. Oh, J.W. Park, H.C. Lee, S. Lee, Effects of tempering temperature on wear resistance and surface roughness of a high speed steel roll, ISIJ Int 41 (2001) 859-865.

[10] L. Xu, S. Wei, F. Xiao, H. Zhou, G. Zhang, J. Li, Effects of carbides on abrasive wear properties and failure behaviours of high speed steels with different alloy element content, Wear 376-377 (2017) 968-974.

[11] M.J. Monteiro, F.C. Rizzo, Effect of chromium content on the oxidation behaviour of highspeed steels under dry and moist air environments, Mater Sci Forum 522-523 (2005) 171-180.

[12] O. Joos, C. Boher, C. Vergne, C. Gaspard, T. Nylen, F. Rezai-Aria, Assessment of oxide scales influence on wear damage of HSM work rolls, Wear 263 (2007) 198-206. 
[13] A. Molinari, G. Straffelin, A. Tomasi, A. Biggi, G. Corbo, Oxidation behaviour of ledeburitic steel for hot rolls, Mater Sci Eng A 280 (2000) 255-262.

[14] N.F. Garza-Montes-de-Oca, W.M. Rainforth, Wear mechanisms experienced by a work roll grade high speed steel under different environmental conditions, Wear 267 (2009) 441448.

[15] Q. Zhu, H.T. Zhu, A.K. Tieu, M. Reid, L.C. Zhang, In-situ investigation of oxidation behaviour in high-speed steel roll material under dry and humid atmospheres, Corros Sci 52 (2010) 27072715.

[16] Q. Zhu, H.T. Zhu, K. Tieu, C. Kong, Three dimensional microstructure study of oxide scale formed on a high-speed steel by means of SEM, FIB and TEM, Corros Sci 53 (2011) 3603-3611.

[17] Q. Zhu, A study of oxidation and wear on high speed steel roll material, PhD thesis, 2012.

[18] L. Zhou, F. Liu, C.S. Liu, D.L Sun, High temperature oxidation behaviour of high speed steel for roll in water vapour, Trans Mater Heat Treat 25 (2004) 134-138.

[19] Y. Yin, J. Sun, S. Teng, C. Niu, Oxidation behaviour of high-speed steel used for hot rolls, Oxid Met 86 (2016) 45-57.

[20] G.Y. Deng, A.K. Tieu, L.H. Su, H.T. Zhu, M. Reid, Q. Zhu, C. Kong, Microstructural study and residual stress measurement of a hot rolling work roll material during isothermal oxidation, Int J Adv Manuf Technol (2019) https://doi.org/10.1007/s00170-019-03305-0.

[21] S.G. Cui, H. Zhu, S. Wan, B. Tran, L. Wang, K. Tieu, Investigation of different inorganic chemical compounds as hot metal forming lubricant by pin-on-disc and hot rolling, Tribology Int 125 (2018) 110-120.

[22] C. Vergne, C. Boher, R. Gras, C. Levaillant, Influence of oxides on friction in hot rolling: experimental investigation and tribological modelling, Wear 260 (2006) 957-975.

[23] N.F. Garza-Montes-de-Oca, R. Colas, W.M. Rainforth, Failure modes of the oxide scale formed on a work roll grade high speed steel, Oxid Met 76 (2011) 149-160.

[24] N.F. Garza-Montes-de-Oca, R. Colas, W.M. Rainforth, On the damage of a work roll grade high speed steel by thermal cycling, Eng Fail Anal 18 (2011) 1576-1583.

[25] M. Pellizzari, D. Cescato, M.G. De Flora, Hot friction and wear behaviour of high speed steel and high chromium iron for rolls, Wear 267 (2014) 467-475.

[26] W.F.H. Zamri, P.B. Kosasih, A.K. Tieu, Q. Zhu, H. Zhu, Variations in the microstructure and mechanical properties of the oxide layer on high speed steel hot rolling work rolls, J Mater Process Technol 212 (2012) 2597-2608.

[27] W.F.H. Zamri, P.B. Kosasih, A.K. Tieu, H. Zhu, Q. Zhu, Finite element modelling of the nanoindentation of layers of porous oxide on high speed steel, Steel Res Int 84 (2013) 13091319.

[28] A.C. Fischer-Cripps, Critical review of analysis and interpretation of nanoindentation test data, Suf Coat Tech 200 (2006) 4153-4165.

[29] W.C. Oliver, G.M. Pharr, Measurement of hardness and elastic modulus by instrumented indentation: Advances in understanding and refinements to methodology, J Mater Res 19 (2004) 3-20.

[30] P. Hosemann, J.G. Swadener, J. Welch, N. Li, Nano-indentation measurement of oxide layers formed in LBE on F/M steels, J Nuclear Mater 377 (2008) 201-205. 
[31] S. Bhowmick, A.N. Kale, V. Jayaram, S.K. Biswas, Contact damage in TiN coatings on steel, Thin Solid Films 436 (2003) 250-258.

[32] S. Math, V. Jayaram, S.K. Biswas, Deformation and failure of a film/substrate system subjected to spherical indentation: Part I. Experimental validation of stresses and strains derived using Hankel transform technique in an elastic film/substrate system, J Mater Res 21 (2006) 774-782.

[33] H. Hertz, Hertz's Miscellaneous Papers, Macmillan and Co., London 1896.

[34] I.N. Sneddon, The relation between load and penetration in the axisymmetric Boussinesq problem for a punch of arbitrary profile, Int J EngSci 3 (1965) 47-57.

[35] T.I. Zohdi, M. Kachanov, I. Sevostianov, On perfectly plastic flow in porous material, Int J Plast 18 (2002) 1649-1659.

[36] J. Paux, R. Brenner, D. Kondo, Plastic yield criterion and hardening of porous single crystals, Int J Solids Struct 132-133 (2018) 80-95.

[37] A.L. Gurson, Continuum theory of ductile rupture by void nucleation and growth: part I yield criteria and flow rules for porous media, J Eng Mater Technol 99 (1977) 2-15.

[38] N. Tvergaard, Influence of voids on shear band instabilities under plane strain conditions, Int J Fracture 17 (1981) 389-407.

[39] A. Needleman, N. Tvergaard, Analysis of the cup-cone fracture in a round tensile bar, Acta Metall 32 (1984) 157-169.

[40] T.H. Wang, T.H. Fang, Y.C. Lin, A numerical study of factors affecting the characterization of nanoindentation on silicon, Mater SciEng A 447 (2007) 244-253.

[41] W.C. Guo, G. Rauchs, W.H. Zhang, J.P. Ponthot, Influence of friction in material characterization in microindentation measurement, J Comp Appl Math 234 (2010) 2183-2192.

[42] J. Gong, J. Wu, Z. Guan, Examination of the indentation size effect in low-load Vickers hardness testing of ceramics, J Europ Ceram Soc 19 (1999) 2625-2631.

[43] G.Z. Voyiadjis, R. Peters, Size effects in nanoindentation: an experimental and analytical study, Acta Mech 211 (2009) 131-153.

[44] M. Liu, C. Lu, K. Tieu, Crystal plasticity finite element method modelling of indentation size effect, Int J Solids Struct 54 (2015) 42-29.

[45] Y. Wang, W. Liu, Y. Ma, Y. Huang, Y. Tang, H. Luo, Q. Yu, Indentation depth dependent micromechanical properties and rate dependent pop-in events of $(\mathrm{Au}, \mathrm{Cu}) 5 \mathrm{Sn}$, Mater Lett 131 (2014) 57-60.

[46] T. Ebisu, S. Horibe, Analysis of the indentation size effect in brittle materials from nanoindentation load-displacement curve, J Europ Ceram Soc 30 (2010) 2419-2426.

[47] A. Tiwari, S. Natarajan, Applied Nanoindentation in Advanced Materials, Wiley, 2017."

[48] Z. Chen, X. Wang, A. Atkinson, N. Brandon, Spherical indentation of porous ceramics: Elasticity and hardness, J Europ Ceram Soc 36 (2016) 1435-1445.

[49] M. Liu, K. Tieu, C. Lu, H. Zhu, G. Deng, A crystal plasticity study of the effect of friction on the evolution of texture and mechanical behaviour in the nano-indentation of an aluminium single crystal, Comp Mater Sci 81 (2014) 30-38.

[50] M. Mata, J. Alcala, The role of friction on sharp indentation, J Mech Phys Solids 52 (2004) 145-165. 
[51] H. Li, A. Ghosh, Y.H. Han, R.C. Bradt, The frictional component of the indentation size effect in low load microhardness testing, J Mater Res 8 (1993) 1028-1032.

[52] Y. Liu, B. Wang, M. Yoshino, S. Roy, H. Lu, R. Komanduri, Combined numerical simulation and nanoindentation for determining mechanical properties of single crystal copper at mesoscale, J Mech Phys Solids 53 (2005) 2718-2741.

[53] X. Chen, Y. Xiang, J.J. Vlassak, Novel technique for measuring the mechanical properties of porous materials by nanoindentation, J Mater Res 21 (2006) 715-724.

[54] P. Clement, S. Meille, J. Chevalier, C. Olagon, Mechanical characterization of highly porous inorganic solids materials by instrumented micro-indentation, Acta Mater 61 (2013) 66496660.

[55] D. Jauffres, C. Yacou, M. Verdier, R. Dendievel, A. Ayral, Mechanical properties of hierarchical porous silica thin films: Experimental characterization by nanoindentation and finite element modelling, Microp Mesop Mater 140 (2011) 120-129. 